NBER WORKING PAPER SERIES

\title{
HAS MONETARY POLICY BECOME \\ MORE EFFECTIVE?
}

\author{
Jean Boivin \\ Marc Giannoni
}

Working Paper 9459

http://www.nber.org/papers/w9459

\author{
NATIONAL BUREAU OF ECONOMIC RESEARCH \\ 1050 Massachusetts Avenue \\ Cambridge, MA 02138 \\ January 2003
}

This paper was previously circulated under the title: "Has Monetary Policy Become Less Powerful?" We thank Ken Kuttner, Serena Ng, Eric Renault, MarkWatson, MichaelWoodford, the editor and an anonymous referee for insightful comments and suggestions. We also thank participants at the AEA meetings, the Society of Economic Dynamics conference and the NBER Monetary Economics meeting for useful suggestions, and Alex Al-Haschimi for research assistance. Jean Boivin thanks the NSF (grant SES-0001751) for financial support. Any errors are the responsibility of the authors. The views expressed herein are those of the authors and not necessarily those of the National Bureau of Economic Research.

(C2003 by Jean Boivin and Marc Giannoni. All rights reserved. Short sections of text not to exceed two paragraphs, may be quoted without explicit permission provided that full credit including notice, is given to the source. 
Has Monetary Policy Become More Effective?

Jean Boivin and Marc Giannoni

NBER Working Paper No. 9459

January 2003, Revised February 2006

JEL No. E52, E3, E32

\section{$\underline{\text { ABSTRACT }}$}

Recent research provides evidence of important changes in the U.S. economic environment over the last 40 years. This appears to be associated with an alteration of the monetary transmission mechanism. In this paper we investigate the implications for the evolution of monetary policy effectiveness. Using an identified VAR over the pre- and post-1980 periods we first provide evidence of a reduction in the effect of monetary policy shocks in the latter period. We then present and estimate a fully specified model that replicates well the dynamic response of output, inflation, and the federal funds rate to monetary policy shocks in both periods. Using the estimated structural model, we perform counterfactual experiments to determine the source of the observed change in the monetary transmission mechanism, as well as in the economy's response to supply and demand shocks. The main finding is that monetary policy has been more stabilizing in the recent past, as a result of both the way it has responded to shocks, but also by ruling out non-fundamental fluctuations.

Jean Boivin

Columbia Business School

821 Uris Hall

3022 Boradway

New York, NY 10027

and NBER

jb903@columbia.edu
Marc P. Giannoni

Columbia Business School

824 Uris Hall

3022 Boradway

New York, NY 10027

mg2190@columbia.edu 


\section{Introduction}

A growing body of evidence, both anecdotal and from formal statistical investigations, suggests that the behavior of the economy has changed in substantial and fundamental ways over the last decades. The important decline in the volatility of U.S. real activity and inflation since the early 1980's is a striking illustration. ${ }^{1}$ This evolving economic environment appears to be associated with an alteration of the propagation mechanism of monetary policy. While some authors, such as Stock and Watson (2003), attribute an important part of the reduced volatility to smaller macroeconomic shocks, there is also evidence of a change in the impact of monetary policy on output and inflation. In particular, studies using vector autoregressions (VAR) find that the impact of monetary policy "shocks" — defined as unexpected exogenous changes in the Federal funds rate - have had a much smaller impact on output and inflation since the beginning of the 1980's. ${ }^{2}$ This is illustrated by circled lines in Figure 1, which show the response of a measure of detrended output and inflation to a monetary shock of the same size, obtained from a VAR estimated separately for the 1959:1 - 1979:2 and 1979:3 - 2002:2 periods. ${ }^{3}$

This evidence raises the possibility that the effect of monetary policy on the economy has changed in important ways. One possible interpretation is that monetary policy has lost some of its influence on the economy. Indeed, various innovations in firms and consumers behavior, perhaps induced by technological progress or financial innovations, might have allowed consumers to better cushion themselves from the impact of interest rate fluctuations. ${ }^{4}$

\footnotetext{
${ }^{1}$ See, e.g., McConnell and Perez-Quiros (2000), Blanchard and Simon (2001), Boivin and Giannoni (2002), Ahmed, Levin and Wilson (2004), Stock and Watson (2002, 2003), Ramey and Vine (2003).

${ }^{2}$ See the NBER working paper version (no. 5145, June 1995) of Bernanke and Mihov (1998), Gertler and Lown (2000), Barth and Ramey (2001) and Boivin and Giannoni (2002) among others. In addition, a special issue of the Federal Reserve Bank of New York's Economic Policy Review (2002) focuses on the monetary transmission mechanism. One of its broad conclusions is that the effects of monetary policy appear somewhat weaker recently than in previous decades (see e.g., Kuttner and Mosser, 2002).

${ }^{3}$ The exact definitions of these variables and how the responses were computed is described in Section 2 below.

${ }^{4}$ McConnell and Perez-Quiros (2000) and Kahn, McConnell and Perez-Quiros (2002) argue that progress in inventory management could explain the lower volatility of GDP after 1984.
} 
This is however not the only possible interpretation. In fact, the response to monetary policy shocks does not only depend on the behavior of households and firms - in short, the private sector — but also on the way monetary policy is conducted. As a striking example, if monetary policy were very effective at influencing output and inflation, and the central bank were able to perfectly offset the effects of exogenous disturbances on these variables, then estimated impulse responses functions to a monetary policy shock should display no response of inflation and output. Thus an alternative interpretation of the change in impulse responses reported in Figure 1 is that monetary policy has more successfully managed to moderate the effects of exogenous disturbances after the early 1980's, possibly by systematically responding more decisively to fluctuations in economic conditions. ${ }^{5}$ In this case, the change in the responses to monetary shocks would not reflect a reduction in monetary policy effectiveness, but rather an improvement in its conduct.

The effectiveness of monetary policy might have changed along other dimensions as well. Not only might monetary policy stabilize more effectively the economy in response to its own shock, but also to other shocks such as real demand and supply disturbances. Another possibility, as suggested by Clarida, Galí and Gertler (2000), is that monetary policy is now more successful at ruling out undesired non-fundamental fluctuations. Furthermore, the size of the policy shocks itself - which could represent random policy mistakes - might have changed over time.

The goal of this paper is to understand the sources of the changes in the monetary transmission mechanism and their implications for the various dimensions of monetary policy effectiveness. We do so by following a two-step strategy. First, using a VAR estimated over the 1959:1-1979:2 and 1979:3-2002:2 periods, we identify a reduced form policy reaction function and the implied policy shocks. This allows us to identify, with a minimum amount of structure, the monetary transmission mechanism, and to characterize its evolution over

\footnotetext{
${ }^{5}$ See Clarida, Galí and Gertler (2000), Cogley and Sargent (2001, 2005), and Boivin (2005), among others, for evidence that U.S. monetary policy has responded more to inflation after the early 1980s.
} 
the past four decades. However, this VAR evidence alone does not allow us to properly interpret the source of changes, as the private sector behavior and expectations are not identified separately from the monetary policy behavior. This motivates the second step of our strategy, which is to use a structural macroeconomic model to interpret the changes in the VAR impulse response functions. We specify a micro-founded general-equilibrium model in the spirit of Rotemberg and Woodford (1997), Christiano, Eichenbaum and Evans (2005), Smets and Wouters $(2003,2004)$, that contains a minimum amount of frictions to account for the observed persistence of output and inflation in U.S. data.

Since one of our objectives is to interpret the evolution of the impulse response functions, we estimate the model by minimizing the distance between the theoretical and empirical (i.e., VAR-based) impulse response functions. Although akin to a calibration exercise, this is a well-defined estimation problem, so that statistical inference can be performed on the structural parameters. Using the estimated structural model, we can then perform a series of counterfactual experiments to determine the causes of the observed changes in the monetary transmission mechanism, and the implications for monetary effectiveness. In particular, we can determine how the response to the different shocks of the model has changed, and to what extent these changes are due to monetary policy.

The main finding of this paper is that monetary policy has been overall more stabilizing since the early 1980's. In particular, we find that the reduced effect of monetary policy shocks in the post-1980 period can be almost entirely explained by a increase of the Fed responsiveness to inflation expectations. We find that the current conduct of monetary policy also stabilizes inflation more effectively in response to supply and demand shocks, and that it stabilizes output more in the face of demand shocks. When confronted with supply shocks, though, we find that the post-1980 policy exacerbates output fluctuations so as to bring output closer to its natural rate. Finally, as Clarida et al. (2000) have suggested, we find that the current policy prevents the existence of non-fundamental - sunspot - fluctuations, 
which was not the case in the pre-1980 period.

The estimated structural model allows us also to make counterfactual exercises in order to determine the sources of the reduction in output and inflation volatility in the post-1980 sample. While we find, as in Stock and Watson (2003), that the change in shocks have contributed to the change in output and inflation volatility, we find in contrast to them that the change in the estimated systematic behavior of the Federal Reserve has played an important role in the reduction of output and inflation volatility in the U.S.

The rest of the paper is organized as follows. Section 2 describes our VAR model of the monetary transmission mechanism, provides statistical evidence of structural change in its parameters and documents the implied reduction in the effect of monetary policy shocks since the early 1980's. Section 3 constructs and estimates a fully-specified general equilibrium model of the U.S. economy. Section 4 uses this model to interpret the nature of the changes in the monetary transmission mechanism through various counterfactual analyses. Section 5 concludes.

\section{Investigating changes in the monetary transmission mechanism}

\subsection{Empirical model}

The first step of our investigation consists of uncovering the monetary policy transmission mechanism. A structural VAR provides a way to do this by imposing just enough restrictions to identify an exogenous policy shocks, without having to specify a complete model of the economy. Our baseline empirical model of the economy is a VAR in variables describing the 
economy $\left(Z_{t}\right)$ as well as monetary policy $\left(R_{t}\right)$

$$
\left(\begin{array}{c}
Z_{t} \\
R_{t}
\end{array}\right)=a+A(L)\left(\begin{array}{c}
Z_{t-1} \\
R_{t-1}
\end{array}\right)+u_{t} .
$$

Three variables are included in the non-policy block $Z_{t}$ : detrended output $\left(\hat{Y}_{t}\right)$ and the inflation rate $\left(\pi_{t}\right)$, as suggested by the theoretical model developed in Section 3, as well as a commodity price measure. ${ }^{6}$ The commodity price inflation, although not formally justified by the theoretical model, is added to limit the extent of a "price-puzzle" in this VAR. ${ }^{7}$ The policy instrument, $R_{t}$, is assumed to be the Federal funds rate. While the Fed's operating procedure has varied in the last four decades, many authors have argued that the Federal funds rate has been the key policy instrument in the U.S. over most of that period (see e.g., Bernanke and Blinder (1992), Bernanke and Mihov (1998)). ${ }^{8}$

In order to identify the policy reaction function and the policy shocks from this VAR, we assume that the economy $\left(Z_{t}\right)$ responds only with a lag to changes in the Fed funds rate. Although debatable, this identifying assumption is consistent with many recent VAR

\footnotetext{
${ }^{6}$ All series are taken from the Standard and Poor's -DRI database. Detrended output is measured as the deviation of the natural logarithm of quarterly real GDP (mnemonic GDPQ) from a linear deterministic trend. The results are robust to the use of alternative detrending methods, including a quadratic trend and a band pass filter (see our NY Fed Staff Report \# 144). The inflation rate is the annualized rate of change in the GDP deflator (mnemonic GDPD) between two consecutive quarters. The commodity price measure is the quarterly average of the monthly spot market commodity price index (mnemonic PSCCOM). The original data set runs from 1959:1 to 2002:2. Four lags are included in the VAR, as determined by the Schwarz information criterion.

${ }^{7}$ This practice is fairly standard in this literature since Sims (1992). An alternative proposed by Bernanke, Boivin and Eliasz (2005) is to incorporate more information using a factor-augmented VAR (FAVAR). As shown in the Appendix A, our VAR results are robust to this alternative.

${ }^{8}$ The Federal funds rate provides probably a less adequate measure of monetary policy stance for the period running from 1979 to 1982, as non-borrowed reserves were set to achieve a level of interest rates consistent with money growth targets, but Cook (1989) argues that the Fed funds rate may still provide a satisfactory indicator during this episode.
} 
analyses. ${ }^{9}$ Under this recursive structure, the identified VAR can be expressed as:

$$
\begin{aligned}
Z_{t} & =b+\sum_{i=1}^{P} B_{i}^{Z} Z_{t-i}+\sum_{i=1}^{P} B_{i}^{R} R_{t-i}+u_{t}^{Z} \\
R_{t} & =\phi^{0}+\sum_{i=0}^{P} C_{i}^{Z} Z_{t-i}+\sum_{i=1}^{P} C_{i}^{R} R_{t-i}+u_{t}^{R} .
\end{aligned}
$$

Equation (2) constitutes an unrestricted specification of the policy reaction function, which can be estimated directly by OLS. As we discuss below, the policy reaction function so identified can be seen as a reduced-form expression for the structural policy rule used in the estimation of the structural model.

Results from VAR models are known to be quite sensitive to their specification. Our simple but standard specification has the virtue of containing the minimum set of variables necessary for our investigation, and yet delivering sensible impulse response functions, broadly consistent with existing results in the literature. Importantly, the key empirical feature that we are trying to explain, namely the reduced effect of monetary shocks on output and inflation, is corroborated by different specifications and identifying assumptions. For instance, Bernanke and Mihov (1998) report a similar reduction in the effect of a policy shock using a much more sophisticated model of the Fed's operating procedure. ${ }^{10}$ Barth and Ramey (2001) reach similar conclusions using instead long-run restrictions. Furthermore, the robustness analysis discussed in the Appendix A shows that the inclusion of more information in our VAR does not affect this conclusion.

\footnotetext{
${ }^{9}$ See for instance Bernanke and Blinder (1992), Rotemberg and Woodford (1997), Bernanke and Mihov (1998) and Christiano, Eichenbaum and Evans (1999).

${ }^{10}$ See NBER working paper version (no. 5145, June 1995) of Bernanke and Mihov (1998).
} 


\subsection{Documenting changes in the effect of monetary policy}

\subsubsection{Stability tests on the reduced form VAR}

The stability of macroeconomic relationships has been investigated in a number of recent papers. The most general evidence is provided by Stock and Watson (1996) who find widespread instability in the bivariate relationships among 76 macroeconomic variables. In the VAR context, mixed results have been obtained. ${ }^{11}$ Boivin (1999) argues that the differences are due mainly to the small sample properties of the stability tests, and to the effect of the number of parameters tested on the power of these tests. He concludes that there is compelling evidence of instability in monetary VARs.

To investigate the stability of the parameters in the VAR described above, we use an heteroskedasticity robust version of the Bai, Lumsdaine and Stock (1998) multivariate stability test. Under the alternative of this test, the VAR parameters are experiencing a discrete shift at some unknown date. The test allows to test jointly for instability of all the parameters of the VAR and if instability is detected, confidence intervals for the break date can be constructed. ${ }^{12}$ Moreover, this class of tests is also known to have power against other alternatives, such as one in which the coefficients follow a random walk (see Stock and Watson, 1998).

The $p$-value of the test applied to our VAR for the null hypothesis of no change is 0.01 , suggesting that its parameters and the implied propagation mechanism have changed at some point in the last four decades. The economic significance of this change is further emphasized by Boivin and Giannoni (2002) who show, using a similar VAR, that the observed reduction in the volatility of inflation and output is explained roughly equally by a reduction in the variance of the shocks and a smaller propagation. ${ }^{13}$

\footnotetext{
${ }^{11}$ Bernanke, Gertler and Watson (1997) and Stock and Watson (2002) find evidence of instability in a monetary VAR, while Bernanke and Mihov (1998) and Christiano, Eichenbaum and Evans (1999) conclude the opposite.

${ }^{12}$ The implementation of the test follows Stock and Watson (2002).

${ }^{13}$ Boivin and Giannoni (2002) report stability tests applied only to subsets of these parameters and also
} 
If we impose on the VAR the structure of the policy rule used in the structural model of Section 3 and apply the test to this equation only, the $p$-value is 0.00 . We can thus already conclude that part of the instability observed in the reduced form VAR arises from changes in the conduct of monetary policy per se.

The $90 \%$ confidence interval for the VAR parameters break date ranges from the fourth quarter of 1977 to the second quarter of 1986. The break dates is thus quite imprecisely estimated. However, this confidence interval is consistent with a structural change in the economy occurring in the early 1980's, as many of the studies mentioned in the introduction have suggested. ${ }^{14}$

\subsubsection{Split-sample estimates of the impulse response functions}

Given this evidence of changes in the economy, we now turn to the implications for the effect of monetary policy. We assess the changes in the effects of monetary policy by comparing impulse response functions of the output gap, inflation, and the Fed funds rate to a monetary policy shock, using the VAR estimated over two different sub-samples. Based on compelling anecdotal evidence regarding the conduct of monetary policy, and on previous empirical studies, while making sure that the samples are not too small, we decided to base our comparison on the following sub-samples: Sample 1 corresponds to the 1959:1-1979:2 period and Sample 2 corresponds to the 1979:3-2002:2 period. When estimating the VAR, only observations from the relevant sub-sample are used, even for the initial lags. The two samples

suggest the presence of instability. Note also that allowing for a break in the constant at the estimated break date does not change the conclusions reached here.

${ }^{14}$ Note that the stability test we have implemented allows for a single discrete break in the variance of the residuals as well as heteroskedasticty that is explained by the lagged dependent variables in the VAR. However, Sims and Zha (2005) argue that a proper account of heteroskedasticity needs to allow for at least two discrete changes in the variance of the residuals, one in the late 1970's and one in the early 1980's. There are numerous differences between our empirical setup and theirs. But one way to check whether the evidence of parameter instability we found is driven by a failure to account for this second shift in the variance, is to determine if there is further evidence of parameter instability on the two sub-samples defined by the identified break date (1982:1). We find no evidence of parameter instability post-1982:1, but the null of stability is rejected at the $1 \%$ level in the pre-1982:1 sample. Moreover, the reduction in the effect of policy that we document below is robust to the exclusion of the 1979:3-1983:4 period from the comparison, once the relevant information is properly accounted (see Appendix A). 
are defined by the quarter in which Fed chairman Paul Volcker started his tenure, which corresponds to the first observation of Sample 2. This date is within the confidence interval of the break date estimate and is consistent with the finding of Boivin (2005) who, estimating a time-varying-parameter model, finds that policy coefficients display an important change around that time. Of course, the changes could be argued to have occurred at other points within the confidence interval of the break date estimates. An alternative would be to start the second sample in 1984:1, a date consistent with some estimates of the date of change in the volatility of the U.S. economy. ${ }^{15}$ However, as we argue in Appendix A, with a proper account of the relevant information, the differences between the pre- and post-break samples we emphasize are robust to this alternative choice of the break date.

Figure 1 displays — for both samples - the impulse response functions to an unexpected unit increase in the Fed funds rate, and the associated 95-percent confidence interval from the unrestricted VAR. ${ }^{16}$ The key result from this comparison is that the response of detrended output and inflation is much less pronounced and persistent since the beginning of the 1980's than in the previous period; the trough of the response of output is about four times larger in Sample 1 than in Sample 2. This result suggests that the effect of a monetary policy shock of a given size was stronger before the 1980's.

Given the imprecision of the estimated impulse response functions, it is difficult to assess directly from the confidence intervals reported in Figure 1 whether the changes in impulse response functions are significant or not. However, we have provided statistical evidence of changes in the parameters of the VAR, and we have shown that these changes imply point estimates of the impulse response functions that are quite different. Moreover, the structural analysis that we perform below establishes that the changes in the impulse response functions are driven almost entirely by changes in the policy reaction function, no matter whether the other structural parameters have changed or not. Since the changes in the estimated

\footnotetext{
${ }^{15}$ See McConnell and Perez-Quiros (2000).

${ }^{16}$ The $95 \%$ confidence intervals were obtained using Kilian's (1998) bootstrap procedure.
} 
policy reaction function are found to be statistically significant, we can thus conclude that the difference in the point estimates of the impulse response function in the two samples are statistically significant. We see these results, together with the existing evidence ${ }^{17}$, as providing compelling evidence of changes in the propagation of monetary policy shocks.

Finally, a by-product of this estimation is a measure of the standard deviation of the monetary policy shocks in the two samples. In the first sample the standard deviation is 0.48 compared to 0.60 in the second sample. Taking these numbers literally, this would suggest that monetary policy has not become more successful in reducing random variations in its instrument, perhaps stemming from policy mistakes. ${ }^{18}$ However, we know from the existing literature that these policy shocks are small, and while they are useful to help us identify the monetary transmission mechanism, they have a marginal contribution in business cycle fluctuations. As a result, one would not expect the loss, or the potential gain for that matter, in monetary policy effectiveness to be important along this dimension.

\section{Structural analysis of the monetary transmission mech-}

\section{anism}

The main goal of this investigation is to determine the implications of these changes for the effectiveness of monetary policy. This requires identifying separately the parameters describing the private sector behavior from those describing the policy behavior. To do so, we estimate a stylized structural model so that it replicates as well as possible the response of the economy to monetary policy shocks. In the next section, we use this model to perform

\footnotetext{
${ }^{17}$ As noted in the introduction, see Barth and Ramey (2001), Gertler and Lown (2000), Boivin and Giannoni (2002), and other papers collected in the special issue of Economic Policy Review (2002).

${ }^{18}$ This result might be surprising at first. However, this is clearly due to the inclusion of the early 1980's in the second sample, where the Fed funds rate was very volatile. While as argued above, the starting date of the sample does not affect the estimated impulse response functions, it does affect size of the policy shocks. For instance, if we start the second sample in 1984:1 instead, the standard deviation of the policy shocks is 0.23 .
} 
counterfactual experiments, to determine the source of the changes in the impulse response functions and volatilities observed for the two samples.

\subsection{A stylized structural model of the U.S. economy}

The model that we consider is set up to be consistent with the structure of the VAR considered in previous sections. It extends the Rotemberg and Woodford (1997) model by adding two key elements that have become fairly standard by now: habit formation in consumption, and inflation inertia. These additional features allow the model to display much more endogenous persistence and to better replicate the response of real output, inflation and the interest rate to an unexpected monetary policy shock, in particular in the pre-1980 sample. At the same time, our model simplifies the models of Christiano et al. (2005) and Smets and Wouters $(2003,2004)$ by leaving aside features of their models that are not necessary to fit the dynamic response of inflation, output and interest rates to monetary policy shocks.

One simplification with respect to Christiano et al. (2005) and Smets and Wouters (2003, 2004 ) is that we consider all interest-rate sensitive expenditure (including what is commonly classified as investment spending) as if it were non-durable consumption. Of course, one may wonder why we are considering habit persistence in the level of aggregate private expenditure, and not merely in consumption. The reason is that models that can successfully account separately for investment and consumption usually assume adjustment costs in the rate of investment spending (e.g., Edge, 2000; Christiano et al., 2005; Altig et al. 2005; Basu and Kimball, 2003). As shown in Woodford (2003, ch. 5, sec. 1.2) in a discussion of our model, this kind of adjustment costs yields a log-linearized Euler equation for investment expenditure that is identical to the one reported below, so that the degree of "habit persistence" assumed here can be interpreted as a proxy for adjustment costs in investment expenditure. ${ }^{19} \mathrm{As}$ a

\footnotetext{
${ }^{19}$ Although our simplification affects the interpretation of the coefficient of "habit persistence", it does not affect the results of the counterfactual experiments we perform below, as we only change the parameters describing the private sector as a group.
} 
result, the fact that we consider all interest-rate sensitive expenditure as if it were nondurable consumption amounts to abstracting from the effects of private expenditures on future production capacities, as discussed in McCallum and Nelson (1999) and Woodford (2003, ch. 4). Since, as shown in Woodford (2003, ch. 5; 2005), a fixed-capital model of the kind we analyze here and the variant of it that separately accounts for investment may be calibrated so as to generate almost identical impulse responses of inflation, output, interest rates and real marginal costs to a monetary shock, our simplification should not dramatically affect the model's predictions for the variables that we seek to explain.

We assume that there is a continuum of households indexed by $j$, each of which seeks to maximize its utility given by

$$
E_{t}\left\{\sum_{T=t}^{\infty} \beta^{T-t}\left[u\left(C_{T}^{j}-\tilde{\eta} C_{T-1}^{j} ; \xi_{T}\right)-v\left(y_{T}(j) ; \xi_{T}\right)\right]\right\}
$$

where $\beta \in(0,1)$ is the household's discount factor, $C_{t}^{j}$ is a Dixit-Stiglitz (1977) aggregate of the household's real expenditure for each of the differentiated goods at date $t, y_{t}(j)$ is the amount of the specialized good that household $j$ supplies at date $t$. The vector $\xi_{t}$ represents disturbances to preferences. We allow the parameter $\tilde{\eta}$ to lie between 0 and 1 , so that the households' utility depends on the deviation of current expenditure $C_{t}^{j}$ from some internal habit stock $\tilde{\eta} C_{t-1}^{j} \cdot{ }^{20}$ As we show below, the presence of habit formation allows us to replicate the hump-shaped response of output to a monetary policy shock.

We assume that financial markets are complete, so that risks are efficiently shared. As a result, all households face an identical intertemporal budget constraint, and choose to consume the same amount at any date. We may therefore drop the superscript $j$ in $C_{t}^{j}$. Furthermore, we assume, as in Rotemberg and Woodford (1997), that households must

\footnotetext{
${ }^{20}$ One specification of the utility function $u$ could be for instance $u=\left(C_{t}-\tilde{\eta} C_{t-1}+M\right)^{1-\rho} /(1-\rho)$, where $M \geq 0$ is large enough for the whole term in parenthesis to be positive (for all dates and all states). Boldrin, Christiano and Fisher (2001) and Christiano et al. (2005) assume a simplified version of this utility function of the form $u=\log \left(C_{t}-\tilde{\eta} C_{t-1}\right)$. In contrast, Amato and Laubach (2004) and Fuhrer (2000) consider monetary models with "multiplicative" habit formation introduced by Abel (1990) and Galí (1994).
} 
choose the index $C_{t}$ at date $t-2$, so that $C_{t+2}=E_{t} C_{t+2} \cdot{ }^{21}$ This assumption is consistent with the identifying restriction imposed in the VAR considered above, according to which both output and inflation are prevented from responding to a contemporaneous monetary shock. Moreover, an assumption of this kind is needed to account for the fact that monetary policy shocks in the U.S. start exerting a significant effect on GDP after two quarters. ${ }^{22}$ In addition, we assume that the government purchases a Dixit-Stiglitz aggregate $G_{t}$ of all goods in the economy. This implies that the aggregate demand for the composite good, $Y_{t}$, satisfies $Y_{t}=C_{t}+G_{t}{ }^{23}$ For consistency with the assumption made in our VAR for the identification of monetary policy shocks, we assume that $G_{t}$ is determined before the interest rate is set in period $t$, so that $G_{t}$ is determined on the basis of information available at date $t-1$.

The first-order conditions for the optimal choice of consumption together with the goods market equilibrium condition just mentioned characterize the link between the interest rate and aggregate demand. We consider log-linear approximations of these equations around a steady state in which there are no exogenous disturbances and prices are stable. As shown in Appendix B, they yield a variant of the intertemporal IS equation

$$
\begin{aligned}
\hat{Y}_{t} & =\eta \hat{Y}_{t-1}+\beta \eta E_{t-2} \hat{Y}_{t+1}-\psi E_{t-2} \hat{r}_{t}^{L}+g_{t} \\
\hat{r}_{t}^{L} & \equiv \sum_{T=t}^{\infty} E_{t}\left(\hat{R}_{T}-\pi_{T+1}\right)
\end{aligned}
$$

where

$$
\begin{aligned}
\psi & \equiv \frac{\sigma(1-\beta \tilde{\eta})}{1+\beta \tilde{\eta}^{2}}>0, \quad \sigma \equiv-\frac{u_{c}}{u_{c c} \bar{C}} \frac{\bar{C}}{\bar{Y}}>0 \\
0 & \leq \eta \equiv \frac{\tilde{\eta}}{1+\beta \tilde{\eta}^{2}} \leq(1+\beta)^{-1}
\end{aligned}
$$

\footnotetext{
${ }^{21}$ Another interpretation of this assumption is that households choose the amount of expenditure using information regarding the state of the economy two periods earlier.

${ }^{22}$ To the extent that $C_{t}$ also represents investment spending, the assumption that it is planned two periods in advance also relates to the time-to-build assumption introduced by Kydland and Prescott (1982).

${ }^{23}$ While $G_{t}$ is associated here with government expenditures, it can more generally represent variations in autonomous (i.e., not interest-rate sensitive) spending.
} 
and $\hat{Y}_{t}$, and $\hat{R}_{t}$ represent respectively percent deviations of aggregate output $Y_{t}$, and the riskless gross nominal interest rate $1+R_{t}$ from their steady-state level, $\pi_{t} \equiv \log \left(P_{t} / P_{t-1}\right)$ is the inflation rate, and $g_{t}$ is an exogenous real demand disturbance that depends on $G_{t}$, past expectations of $G_{t}$ and the preference disturbance $\xi_{t} \cdot{ }^{24}$ Note that because $G_{t}$ is determined at $t-1$, both $g_{t}$ and $\hat{Y}_{t}$ are determined at date $t-1$. The variable $\hat{r}_{t}^{L}$ denotes percent deviations of the long term real interest rate, which happens to coincide with the marginal utility of additional income. In the absence of habit-formation, the coefficient $\sigma$ would represent the intertemporal elasticity of substitution (EIS) of private expenditure evaluated at the steadystate times the consumption share. ${ }^{25}$ Since it is difficult to interpret this parameter in the presence of habit formation, we prefer to focus on a pseudo-EIS, $\psi$, which is the elasticity of expected output growth with respect to changes in the real return, conditional on output growth remaining constant in other periods. ${ }^{26}$ As (4) makes clear, real output depends negatively on the long-term real interest rate and positively on past and expected future output, due to habit persistence. ${ }^{27}$

Monetary policy has real effects in this model, because it is assumed that not all suppliers are able to adjust their prices in response to disturbances. Specifically, we assume as in Calvo (1983) that a fraction $(1-\alpha)$ of suppliers can choose a new price at the end of any given period, and that the price-setters who are allowed to change their price are chosen independently of their history of price changes. The timing that we assume implies that the sellers who get to change their prices at date $t$ must decide on the basis of information

\footnotetext{
${ }^{24}$ We view the variables used in the VAR - detrended output, the inflation rate, and the Fed funds rate as the empirical counterparts of $\hat{Y}_{t}, \pi_{t}$ and $\hat{R}_{t}$.

${ }^{25}$ As mentioned above this coefficient may also serve as a proxy for adjustment costs in investment expenditure.

${ }^{26}$ This can be seen by taking first differences of equation (4), and combining with (5).

${ }^{27}$ Note that in the absence of habit formation, (4) reduces to $\hat{Y}_{t}=-\sigma E_{t-2} \hat{r}_{t}^{L}+g_{t}$, so that after taking first differences and using (5) we obtain the familiar output Euler equation

$$
\hat{Y}_{t}=E_{t} \hat{Y}_{t+1}-\sigma E_{t-2}\left(\hat{R}_{t}-\pi_{t+1}\right)+\left(g_{t}-E_{t} g_{t+1}\right)
$$
}

where output depends negatively on the short-term real interest rate. 
available at date $t-1$, which is again consistent with the assumption made in the structural VAR to identify monetary policy shocks. Following Christiano et al. (2005) and Smets and Wouters $(2003,2004)$, we assume that if a price is not re-optimized, it is indexed to lagged inflation according to the rule

$$
\log p_{t}(z)=\log p_{t-1}(z)+\gamma \pi_{t-1}
$$

for some $0 \leq \gamma \leq 1$. As shown in Appendix B, a log-linearization of the optimal pricing condition and of the law of motion for the aggregate price level yields the following variant of the new-Keynesian aggregate supply equation

$$
\pi_{t}-\gamma \pi_{t-1}=\xi E_{t-1} \hat{s}_{t}+\beta E_{t-1}\left(\pi_{t+1}-\gamma \pi_{t}\right)
$$

where

$$
\hat{s}_{t} \equiv \omega \hat{Y}_{t}-\hat{r}_{t}^{L}-q_{t}
$$

represents percent deviations from steady-state of the average (across firms) real marginal cost, $\omega>0$ is the elasticity of the marginal disutility of producing output with respect to an increase in output, and $\xi \equiv \frac{(1-\alpha)(1-\alpha \beta)}{(1+\omega \theta) \alpha}>0$ is a parameter that depends on the degree of price stickiness, $\alpha$, the elasticity of demand, $\theta$, and $\omega$. The exogenous variable $q_{t}$ is a positive supply shock that measures reductions in the disutility of producing output. ${ }^{28}$ It can be shown that $\hat{s}_{t}$ relates to a measure of the output gap, $\hat{Y}_{t}-\hat{Y}_{t}^{n}$, defined as the percent deviation of output from its natural rate whereby the natural rate we mean the equilibrium output that would obtain in the absence of price rigidities (see Appendix B).

As in the standard New Keynesian supply equation, inflation depends positively on the

\footnotetext{
${ }^{28}$ Instead of assuming that the household derives disutility from supplying its specialized good, we could assume that it derives disutility from supplying labor, and that the goods are produced using labor and some fixed amount of capital. In such a case, $q_{t}$ would also include fluctuations in total factor productivity as well as in the disutility of labor supply.
} 
expectation of the gap between output and its natural rate, as well as on the expectation of future inflation. Here it is the expectation formed at date $t-1$ that is relevant for the determination of period-t inflation, as sellers are assumed to set their prices on the basis of information available at date $t-1$. In addition, inflation depends on past inflation. While the aggregate supply equation (6) is very stylized, it nests as special cases some popular models that have very different implications, in particular regarding the degree of persistence in inflation. Except for the fact that pricing decisions at date $t$ are taken here on the basis information available at date $t-1$, (6) reduces to the basic New Keynesian aggregate supply equation with Calvo pricing when $\gamma=0$ and $\eta=0$. Alternatively, when $\gamma=1, \eta=0$, and $\beta=1$, (6) is similar to the aggregate supply equation of Fuhrer and Moore (1995). We assume that prices which are not re-optimized are adjusted to lagged inflation, but we could have derived an equation almost identical to (6) — with different restrictions on the model parameters - by assuming instead that some sellers are not rational and that they set their prices according to a simple rule of thumb, as in Galí and Gertler (1999).

Finally, the model is closed by a description of the central bank behavior. To the extent that the central bank is forward-looking, the coefficients of the VAR policy equation will subsume policy parameters - i.e., the parameters characterizing the Fed's systematic behavior — as well as the remaining parameters needed to form the expectations, conditional on the time- $t$ information set. To distinguish between changes in the private sector and policy behavior we need to specify a structural form of the reaction function. The forward-looking Taylor rule is one such policy reaction that is consistent with the reduced form policy of the VAR. It takes the form

$$
\hat{R}_{t}=\phi_{\pi} E_{t} \pi_{t+h_{\pi}}+\phi_{y} E_{t} \hat{Y}_{t+h_{y}}+\rho_{1} \hat{R}_{t-1}+\rho_{2} \hat{R}_{t-2}+\varepsilon_{t}
$$

where $\varepsilon_{t}$ is an unforecastable random variable that represents monetary policy shocks. For the horizons $h_{\pi}=0$ and $h_{y}=0$, equation (8) corresponds to the popular rule proposed 
by Taylor (1993), augmented by lags of the Fed funds rate. ${ }^{29}$ As another special case, the baseline case considered by Clarida, Galí and Gertler (2000) obtains when $h_{\pi}=1$ and $h_{y}=$ 1. 3031 As in Taylor (1993), we assume that the Federal Reserve has responded to fluctuations of output around a deterministic trend over the sample considered. ${ }^{32}$ Alternatively, we could assume that the Fed has responded to the welfare-relevant output gap, $\hat{Y}_{t}-\hat{Y}_{t}^{n}$. Even though the model suggests that optimal policy should respond to such an output gap, ${ }^{33}$ we view it as more realistic to characterize historical policy in terms of detrended output which displays expansion and recession periods in line with conventional accounts, such as those from the NBER. As Woodford (2001) points out, the welfare-relevant output gap derived from models like ours differs considerably from detrended output, and might even be negatively correlated with it. A policy that responds to such an output gap could thus in principle result in outcomes that might be very different from those observed. However, given the small values of the coefficients $\phi_{y}$ that we estimate below, the measure of activity considered in the policy rule plays very little role for our results. ${ }^{34}$

The model that we use for the joint determination of the evolution of inflation, real output and the short-run and long-run interest rates (all expressed in terms of deviations from their steady state), can be summarized by the "IS block" (4) - (5), the aggregate supply equation (6) - (7), and the interest-rate feedback rule (8). The resulting system

\footnotetext{
${ }^{29}$ The Fed funds rate is known to display a lot of persistence. This phenomenon might arise from a Fed's interest-rate smoothing concern or could reflect optimal policy under commitment (cf. Woodford, 1999). The specification that we consider involves two lags of the interest rate. This turns out to be the most parsimonious specification that is not rejected by the test of overidentifying restrictions.

${ }^{30}$ These authors estimate such a rule by GMM, in the single equation framework, assuming rational expectations on the part of the central bank. In contrast, we estimate this equation together with the rest of our structural model as described in the next sub-section.

${ }^{31}$ Giannoni and Woodford (2003) characterize optimal interest-rate rules for models similar to the one presented here (but slightly simpler). They argue that while it is desirable to set the interest rate as a function of forecasts of inflation and output gap, there is little ground for letting interest-rate decisions respond to forecasts longer than a few quarters in the future.

${ }^{32}$ As mentioned in footnote 6 , we removed a linear trend from log output, but our results are robust to alternative detrending methods.

${ }^{33}$ See Giannoni and Woodford (2004) for a characterization of optimal monetary policy in a similar model.

${ }^{34} \mathrm{As}$ will become clear in the next section, our estimation method has the property that the estimate of $\phi_{y}$ is the same whether we consider detrended output or the output gap in (8).
} 
of linear difference equations can then be solved using standard methods (e.g., King and Watson, 1998; McCallum, 1998).

For some parameter configurations, the model may result in an indeterminate equilibrium. ${ }^{35}$ This may arise when the policy reaction function involves too little a response to changes in economic conditions, as Clarida et al. (2000) argue might have been the case for the pre-Volcker period. ${ }^{36}$ This is in fact one dimension along which monetary policy could have become more effective and that we wish to investigate. But allowing parameters configuration to lie in the indeterminate region raises some difficulty: whenever this is the case, one equilibrium must be selected and there is unfortunately no natural criterion to select a particular one. So in the case of indeterminacy, the particular equilibrium that we select is the minimum-state-variable solution advocated by McCallum (1983), i.e., the single bubble-free solution. This solution corresponds to a situation where the economy could be subject to sunspots fluctuations, but there happens to be no such shock. While we recognize that the criterion that we adopt to select a solution may not be the only one, we find it appealing, in particular when compared to the alternative of ruling out a priori the possibility of indeterminacy. For instance, it allows us to implement the estimation strategy described in the next section, even when parameter configurations yield an indeterminate equilibrium. ${ }^{37}$

\footnotetext{
${ }^{35}$ This means that for any bounded solution $\left\{z_{t}\right\}$, where $z_{t}$ is the vector of variables of interest $\left[\hat{Y}_{t}, \pi_{t}, \hat{R}_{t}\right]^{\prime}$, there exists another bounded solution of the form

$$
z_{t}^{\prime}=z_{t}+v \epsilon_{t}
$$

where $v$ is an appropriately chosen (nonzero) vector, and the stochastic process $\left\{\epsilon_{t}\right\}$ may involve arbitrarily large fluctuations, that may or may not be correlated with the fundamental disturbances $\left\{\varepsilon_{t}, g_{t}, q_{t}\right\}$. It follows that for such a parameter configuration, the model may involve arbitrarily large fluctuations of real output, inflation and the interest rate, independently of the size of the fundamental shocks.

${ }^{36}$ See, e.g., Woodford (2003, ch. 2 and 4) for a discussion of the problem of indeterminacy of the equilibrium in monetary models of the kind analyzed here.

${ }^{37}$ Lubik and Schorfheide (2004) propose an alternative approach that allows for the possibility of multiple equilibria in the estimation of DSGE models. However, unlike the estimation strategy discussed below, their Bayesian approach requires a complete specification of the shock processes and of all prior distributions.
} 


\subsection{Estimation of the structural model}

\subsubsection{Minimum distance estimation of the structural parameters}

We now turn to the estimation of the structural model just described. ${ }^{38}$ In section 2 , we estimated a structural VAR, that allowed us to generate impulse response functions to monetary policy innovations. The model described in the previous subsection is consistent with the identifying assumption imposed in the VAR, and delivers impulse responses of the variables of interest for a given set of structural parameters. Our econometric methodology involves selecting the structural parameters that minimize the distance between the estimated VAR responses and the model-based responses. In a way, this can be seen as a calibration exercise. As we now discuss, however, it is a well-defined econometric exercise that can be seen as an application of "semi-parametric indirect inference" (Dridi, Guay and Renault, 2005). ${ }^{39}$

More formally, we consider the vector of structural parameters for Sample $s, \Delta_{s}$, the vector $\Omega_{s}$ containing the identified VAR coefficients and $G_{V}\left(\Omega_{s}\right)$, the vector-valued function that collects the $V A R$-based impulse response functions of output, inflation and the interest rate to a monetary policy innovation. In addition, we denote by $G_{M}\left(\Delta_{s}\right)$ the corresponding vector-valued function that collects the model-based impulse response functions yielded by its rational expectations solution. Let $G\left(\Omega_{s}, \Delta_{s}\right) \equiv G_{M}\left(\Delta_{s}\right)-G_{V}\left(\Omega_{s}\right)$. Having estimated $\Omega_{s}$ as described in Section 2, we minimize

$$
L\left(\Delta_{s}\right)=G\left(\hat{\Omega}_{s}, \Delta_{s}\right)^{\prime} W_{s} G\left(\hat{\Omega}_{s}, \Delta_{s}\right)
$$

with respect to $\Delta_{s}$ to obtain the minimum distance estimator $\hat{\Delta}_{s}$, where $W_{s}$ is a positive definite weighting matrix which we discuss below.

\footnotetext{
${ }^{38}$ A similar estimation procedure can be found in Rotemberg and Woodford (1997), Amato and Laubach (2003), Gilchrist and Williams (2000) and Christiano et al. (2005).

${ }^{39}$ Our estimation method is also similar in spirit to the specification test used by Cogley and Nason (1995), although it was based on matching autocorrelation functions and they were not concerned with the estimation of the structural parameters.
} 
We find this estimation strategy appealing for several reasons. First, since we are interested in explaining the observed changes in the impulse response function to a monetary shock in the two samples considered, it is natural to estimate the structural parameters directly on the basis of the impulse responses functions. Certainly, more efficient estimates of the structural parameters could be obtained by exploiting the response of the economy to other shocks. But this potential efficiency gain has to be weighted against the cost of additional identifying assumptions that would be required. Moreover, to the extent that the model is unable to explain all the features of the data, the estimation on the basis of responses to monetary shocks allows us to focus the estimation on the relevant empirical features of the data that we seek to explain. In this sense, the estimation approach is robust to the identification of other shocks and to the specification of parts of the model that are not related to the impulse response functions we are interested in. ${ }^{40}$ Specifically, while the endogenous variables are affected by demand and supply shocks $g_{t}$ and $q_{t}$ in the theoretical model, our econometric strategy allows us to estimate the structural parameters of interests without estimating the parameters that characterize the stochastic processes $\left\{g_{t}\right\}$ and $\left\{q_{t}\right\}$. Finally, as Hall (2001) pointed out, estimation through impulse response functions has an important advantage over the application of GMM to Euler equations: it indirectly imposes the model's boundary conditions. ${ }^{41}$

Our structural model involves a total of ten structural parameters: $\left\{\phi_{\pi}, \phi_{y}, \rho_{1}, \rho_{2}, \beta, \psi, \xi\right.$, $\omega, \eta, \gamma\}$. All of these parameters could in principle be separately identified from the impulse response functions to a monetary policy shock. However, in order to reduce the dimension of the estimation, we calibrate $\beta$ to 0.99 , because it can be identified directly from first moments of the data. In fact $\beta^{-1}$ corresponds to the steady-state gross real rate of return,

\footnotetext{
${ }^{40}$ The robustness of this estimation approach to a misspecification of the theoretical model is discussed more generally in Dridi and Renault (2001).

${ }^{41}$ In our model, terminal conditions are automatically satisfied once we restrict ourselves to bounded fluctuations of the endogenous variables around the steady state. The estimation method thus retains the advantage mentioned by Hall (2001) as it incorporates the assumption that endogenous variables are bounded.
} 
which is approximately 1.01 on average. We thus attempt to estimate the remaining nine parameters $\Delta=\left\{\phi_{\pi}, \phi_{y}, \rho_{1}, \rho_{2}, \psi, \xi, \omega, \eta, \gamma\right\}$ by matching the model-based impulse response functions with those of the VAR, subject to the model constraints on the sign and magnitude of the parameters. ${ }^{42}$ We consider the responses of the variables over the first sixteen quarters following the monetary shock. This choice is motivated by the fact that most of the difference in the output response in two samples occurs within this horizon. Moreover, this corresponds approximately to the time that it takes for output to return to its initial level, following a monetary policy shock.

To estimate the structural parameters, we also need to determine an asymptotically nonstochastic weighting matrix $W_{s}$ indicated in (9). To account for the fact that some points of the impulse response functions are less precisely estimated than others, we use a diagonal weighting matrix that involves the inverse of each impulse response's variance on the main diagonal. $^{43}$

\subsubsection{Estimation of the forecasting horizon}

The estimation of the policy reaction function requires the specification of the horizons $h_{\pi}$ and $h_{y}$. Such horizons are usually specified on a priori grounds, based on what is thought to be reasonable lags for the effect of monetary policy on the economy. But the horizon that a central bank should be considering is not clear in theory. While forward-looking rules are often motivated from the existence of lags in the effect of monetary policy, there is also a case to be made for backward-looking rules, which might provide more stability. Given

\footnotetext{
${ }^{42}$ In turns out however that the parameter $\omega$ is not well identified as the objective function appears to be very flat with respect to $\omega$. We thus decided to calibrate $\omega$ to 0.47 , the value found in Rotemberg and Woodford (1997).

${ }^{43}$ The intuition for efficient GMM estimation would suggest to use the complete variance-covariance matrix of impulse response functions as a weighting matrix. It should be noted however that this seems infeasible in the present context. In fact, the impulse response functions are non-linear functions of the underlying structural parameters. Consequently, if the number of impulse response points we are trying to match is larger than the number of structural parameters - as it would be the case if our structural model were the true one - the joint distribution of the impulse response points we use in the estimation would be singular. Hence, the variance-covariance matrix would be ill-behaved and the usual asymptotic theory for the $J$-test would not apply.
} 
the absence of a clear criterion to select the horizon a priori and, importantly, given the sensitivity of the results to this choice, it appears desirable to infer the horizon from the data.

As the forward-looking rule (8) is just an over-identified version of equation (2), one can select the horizon that minimizes the distance of the over-identified model from the unrestricted model. A measure of this distance is provided by the Hansen $J$-test. We thus select the horizon minimizing this test statistic. As a by-product, this statistic provides a measure of the accuracy of the specification - other than the horizon - embedded in equation (8).

Table 1 reports the $p$-values of the $J$-test for all combinations of $h_{\pi}$ and $h_{y}$ up to 4 quarters, and for the two samples. The best horizon, i.e., the one with the highest $p$-value, is $h_{\pi}=3$ and $h_{y}=0$, for the 1959:1-1979:2 period and $h_{\pi}=2, h_{y}=0$, respectively for the 1979:3-2002:2 period. For these horizons, the forward-looking Taylor rule specification is not rejected at the $5 \%$ level. Noting that a $95 \%$ confidence interval for these horizons would include any combination $\left(h_{\pi}, h_{y}\right)$ with a $p$-value larger than $5 \%$, the table suggests that within the set of horizons less than or equal to four, the horizons are fairly precisely estimated.

\subsection{Estimation results}

Table 2 reports the structural parameters' estimates, along with the associated standard deviations for both samples. Note first that the degree of habit formation and inflation inertia are similar in both samples, and remain close to, or on the theoretical upper bounds imposed in the estimation. The fact that the degree of inflation inertia $\gamma$ is estimated to be 1 implies that our estimated aggregate supply equation is very similar to the one proposed by Fuhrer and Moore (1995). Looking next at the remaining parameters describing the behavior of the private sector, the main differences between the two samples are in terms 
of the sensitivity of output to the long-run interest rate in the IS curve, $\psi$, and the slope of the Phillips curve, $\xi$ : from Sample 1 to Sample 2, $\psi$ increases from 0.50 to 0.66 while $\xi$ falls from 0.011 to 0.008 . While we cannot separately identify the parameters $\theta$ and $\alpha$ from the estimated parameter $\xi$, it is interesting to observe that for an assumed desired markup of prices over marginal costs of $10 \%$ (so that $\theta /(\theta-1)=1.1$ ), as is often considered in the literature, the implied average duration between price reoptimizations, $(1-\alpha)^{-1}$, is 4.4 quarters in the first sample and 5.1 quarters in the second sample. However, given that prices are automatically indexed to lagged inflation every quarter, firms must not wait for an implausibly long amount of time between price changes. Our results appear thus broadly consistent with the survey evidence reported by Blinder (1994), according to which prices are maintained constant for an average of 3 quarters.

Overall, the estimated parameters of the private sector suggest that detrended output has become more sensitive to the real rate of return, and that inflation responds slightly less to changes in the real marginal cost, maybe due to a possible increase in price rigidity (i.e., an increase in the probability $\alpha$ ). This implies, everything else equal, that changes in the instrument of monetary policy should have had a stronger effect on output after 1980.

It is difficult to provide justifications for changes in certain "deep" parameters, such as those of the utility function embedded in $\psi$. Although we doubt that the intertemporal elasticity of substitution has changed substantially, we view instead these estimates as capturing the fact that the private sector of the economy has reacted more strongly to changes in interest rates in the post-1980 sample than in the pre-1980 sample. Moreover, rather than ruling out changes in the private sector parameters a priori, in the next section we account for these changes and determine whether or not they affect our conclusions about the effectiveness of monetary policy. We find that they do not.

Turning to the policy parameters, the main result is that the response coefficient of the Federal funds rate to inflation is about twice as large in the second sample than in the first. 
This is consistent with the evidence obtained by Clarida et al. (2000), Cogley and Sargent (2001, 2005), Boivin (2005), among others, using very different empirical strategies. Even though the policy coefficient on output (or output gap) fluctuations is typically estimated to be smaller than the coefficient on inflation, our estimated coefficient on output fluctuations is insignificant in the context of our forward-looking interest rate rule.

An important implication is that in the first sample, the configuration of estimated parameters yields an indeterminate rational expectation equilibrium, as in Clarida et al. (2000). This is not the case in the second sample. There is a strong presumption that this is due to the weakness of the central bank response in the first sample, thus implying that monetary policy became more effective along that dimension. ${ }^{44}$ However, this cannot be asserted definitely without taking into account the changes in the other structural parameters. We investigate this issue in the counterfactual experiments of the next section.

Figure 1 plots both the impulse response functions estimated from the VAR (circles), along with their 95 percent confidence intervals, and the corresponding impulse response functions generated by the estimated structural model (solid lines), for both samples. Notice that the model is able to replicate quite precisely both the magnitude and the persistence of the impulse responses generated by the VAR, and the model-based impulse responses remain consistently within the confidence interval. ${ }^{45}$ For the first sample, the model reproduces reasonably well the hump-shaped response of output, the progressive decline in inflation, and the response of the interest rate. For the second sample, the fit is even better. The model captures the rapid decline followed by a return to steady state, both in inflation and output, and it tracks the response of the interest rate.

\footnotetext{
${ }^{44}$ In fact, by plotting the number of unstable eigenvalues of the dynamic system characterizing our estimated model in the $\left(\phi_{\pi}, \phi_{y}\right)$ space (not reported here), we observe that the equilibrium would be determinate for values of $\phi_{\pi}$ above 0.33 and values of $\phi_{y}$ above 0.04 .

${ }^{45}$ The only exception is the response of inflation the first two periods after the shock in Sample 1.
} 


\section{Explaining the changes in the economy}

Having argued that our model replicates reasonably well the effects of monetary shocks on output, inflation and the interest rate in both samples, we proceed with a model-based counterfactual analysis to provide an explanation for the changes in the economy, and investigate whether monetary policy has become more effective. In these counterfactual experiments, we characterize the behavior of monetary policy by the set of monetary policy parameters $\Delta_{s}^{M P}=\left\{\phi^{\pi}, \phi^{y}, \rho_{1}, \rho_{2}\right\}$, and the behavior of the private sector by the set of parameters $\Delta_{s}^{P S}=\{\psi, \xi, \omega, \eta, \gamma\}$.

We first determine whether it is monetary policy or the behavior of the private sector that has been instrumental in removing indeterminacies of the rational expectations equilibrium in the post-1980 period. We then seek to determine to what extent the reduced effect of monetary policy shocks in the post-80 sample is due to an improvement in monetary policy or a change in the private sector's behavior. Next, we assess the relevance of monetary policy and the private sector in accounting for changes in the response to real demand and supply disturbances. Finally, we discuss the extent to which the reduction in output and inflation volatility is attributable to changes in monetary policy, private sector behavior, or exogenous shocks.

\subsection{Indeterminacy}

In the previous section we documented the presence of an indeterminate equilibrium in the pre-1979 period. To determine the cause of indeterminacy, Table 3 reports for various combinations of the estimated private sector $\left(\Delta_{s}^{P S}\right)$ and monetary policy parameters $\left(\Delta_{s}^{M P}\right)$ whether or not they involve a unique rational expectations equilibrium. This Table reveals that it is indeed monetary policy that is the source of indeterminacy in the first sample, as in Clarida et al. (2000). In fact, if the monetary policy rule estimated for the pre-1979 period had been maintained in the second sample, an indeterminate equilibrium would have 
resulted. In contrast, the recent conduct of monetary policy would have would have ruled out non-fundamental fluctuations in the first sample. This is thus clearly a dimension along which monetary policy has become more effective.

\subsection{Responses to exogenous disturbances}

Figure 2 displays the impulse response functions generated by the model to an innovation - a unit increase - in each of the three exogenous disturbances $\varepsilon_{t}, g_{t}$, and $q_{t}$. Each panel of Figure 2 contains impulse responses for the four possible combinations of monetary policy $\left(\Delta_{s}^{M P}\right)$ and private sector $\left(\Delta_{s}^{P S}\right)$ parameters, where $s=1$ for the 1959:1-1979:2 period and $s=2$ for the 1979:3-2002:2 period. Since the equilibrium is indeterminate in the case of the monetary policy rule of sample 1, the impulse responses and standard deviations associated with that monetary policy rule are not uniquely determined. As discussed above, we report those implied by the single bubble-free equilibrium. Since the latter equilibrium excludes a priori non-fundamental disturbances, it should result in a lower volatility and smaller impulse responses than would be the case for most alternative equilibria possible with that policy rule. Thus by selecting the bubble-free equilibrium, we are depicting a relatively favorable picture of the policy rule of sample 1 .

The responses to the monetary shock (in the first column) clearly show that the observed change in the monetary transmission mechanism is due to a change in the systematic conduct

of monetary policy. A comparison of the two sets of responses $\left(\Delta_{1}^{M P}, \Delta_{1}^{P S}\right)$ and $\left(\Delta_{1}^{M P}, \Delta_{2}^{P S}\right)$ - i.e. maintaining monetary policy as estimated in the first sample — reveals that, if anything, the change in the private sector implies a larger response of output, not smaller one. This is consistent with the fact that we have estimated a larger values of $\psi$ in the second sample. The inflation response is almost unaffected by the change in parameters of the private sector, in particular in sample 2. For all three variables, a comparison of the impulse responses $\left(\Delta_{2}^{M P}, \Delta_{1}^{P S}\right)$ and $\left(\Delta_{2}^{M P}, \Delta_{2}^{P S}\right)$ - i.e. maintaining monetary policy as 
estimated in the second sample — suggests that the change in the structural parameters has almost no effect on the impulse response functions.

The striking result, however is that the observed reduction in the magnitude of the impulse responses is almost entirely attributable to monetary policy. In fact, by changing monetary policy and maintaining the structural parameters fixed - i.e., by comparing the lines $\left(\Delta_{1}^{M P}, \Delta_{1}^{P S}\right)$ to $\left(\Delta_{2}^{M P}, \Delta_{1}^{P S}\right)$, and $\left(\Delta_{1}^{M P}, \Delta_{2}^{P S}\right)$ to $\left(\Delta_{2}^{M P}, \Delta_{2}^{P S}\right)$ - we observe that the responses of output and inflation associated with the policy estimated for the second sample involve considerably less variation than those associated with the policy of Sample 1. Maintaining the structural parameters constant at $\Delta_{1}^{P S}$, a change in policy from $\Delta_{1}^{M P}$ to $\Delta_{2}^{M P}$ almost entirely explains the impulse responses $\left(\Delta_{2}^{M P}, \Delta_{2}^{P S}\right)$ obtained in the second period. This counterfactual experiment thus suggests that the change in the estimated impulse responses to a monetary shock, first reported in Figure 1, is attributable almost entirely to a change in the systematic conduct of monetary policy. The fact that the response of output and inflation has become considerably smaller in the post- 80 period thus does not appear to reflect a diminished effect of monetary policy on these variables. Rather, our analysis suggests that it is the fact that monetary policy has been reacting more strongly to fluctuations in expected inflation that has helped stabilize the economy in response to monetary shocks.

The second column of Figure 2, which plots the counterfactual responses to a real demand disturbance - i.e., an innovations in $g_{t}$ - conveys a similar message. ${ }^{46}$ While the responses of output, inflation and the interest rate are slightly smaller with the private sector parameters of Sample 2 - comparing $\left(\Delta_{1}^{M P}, \Delta_{1}^{P S}\right)$ and $\left(\Delta_{1}^{M P}, \Delta_{2}^{P S}\right)$ - most of the change in the impulse response functions between Sample 1 and Sample 2 is explained by a change in monetary policy from $\Delta_{1}^{M P}$ to $\Delta_{2}^{M P}$.

The last column of Figure 2 displays impulse response functions to a positive supply shock, i.e., an innovation in $q_{t} \cdot{ }^{47}$ Again, the change in parameters of the private sector play

\footnotetext{
${ }^{46}$ Note that because $g_{t+1}$ is predetermined, as discussed in Section 3, an unexpected demand disturbance at date $t$ does not affect output before date $t+1$.

${ }^{47}$ Note that the exogenous shock in the aggregate supply equation is $E_{t-1} q_{t}$, so that an unexpected supply
} 
a smaller role than monetary policy in affecting the impulse response functions. The inflation responses suggest that the change in monetary policy is responsible for a smaller and less persistent response of inflation in the second sample. However, while the monetary policy rule of sample 1 results in a fairly stable response of output, policy in sample 2 stimulates output considerably. In fact, by responding more aggressively to expected inflation, monetary policy in sample 2 mitigates the deflationary effects of a positive supply shock by lowering interest rates more on impact, which stimulates output. ${ }^{48}$ Stimulating output in such circumstances brings it closer to its natural rate, i.e., the equilibrium output that obtains with flexible prices as it is also positively affected by a supply shock.

\subsection{Volatility}

Many recent papers have documented a "great moderation" in the volatility of U.S. economic activity and inflation since the early 1980's. ${ }^{49}$ In fact the standard deviations of both detrended output and inflation fell by more than one third between the pre- and post- 80 samples. As we just discussed, while monetary policy rule of the post-80 period contributes to reducing the response of output and inflation to both monetary shocks and real demand shocks, it appears to increase the output response to supply shocks. It is thus not clear a priori, to what extent the reduction in volatility can be explained by changes in policy, in parameters describing the private sector, and in the shock processes. To understand this, we turn to a simulation of our model under alternative combinations of estimated monetary policy, parameters of the private sector and exogenous shocks. Of course all results presented below assume that the model is well specified. In the previous subsection, we required that the model correctly characterizes not the response of the endogenous variables to innovations

disturbance at date $t$ does not affect inflation before date $t+1$.

${ }^{48}$ Inverserly, in the face of an adverse supply shock, the post-80 monetary policy is more restrictive and contributes to a greater slowdown than the pre-80 policy.

${ }^{49}$ See, e.g., McConnell and Perez-Quiros (2000), Blanchard and Simon (2001), Boivin and Giannoni (2002), Ahmed, Levin and Wilson (2004), Stock and Watson (2002, 2003), Ramey and Vine (2003). 
in the particular shocks. Now, we assume in addition that the exogenous shock processes be correctly specified.

In order to perform counterfactual model simulations, we need to estimate the stochastic processes of the three disturbances $\left\{\varepsilon_{t}, g_{t}, q_{t}\right\}$. Combining again the identified VAR of Section 2 with the structural model, we can extract a time series for the vector of exogenous variables $x_{t} \equiv\left[\varepsilon_{t}, g_{t+1}, E_{t} q_{t+1}\right]^{\prime}$, all known at date $t$, along the lines of Rotemberg and Woodford (1997). First, we rewrite our structural VAR in companion form as

$$
\bar{Z}_{t}=B \bar{Z}_{t-1}+\bar{u}_{t}
$$

where $\bar{Z}_{t}$ is a vector containing all the variables of the VAR and their lags, and $\bar{u}_{t}$ is an unforecastable vector. Second, using the structural equations (4) - (8), and the estimated parameters, we can express the shocks as a function of past, present and expected future values of output, inflation and the interest rate. It follows that the vector of exogenous variables $x_{t}$ can be expressed as a function of present and expected future values of a vector $\tilde{Z}_{t}$ which contains the theoretical variables corresponding to those in $\bar{Z}_{t}$. Third, assuming that expectations of future variables in the model correspond to the VAR forecasts, so that $E_{t} \tilde{Z}_{t+j}=E_{t} \bar{Z}_{t+j}=B^{j} \bar{Z}_{t}$ for all $j>0,{ }^{50}$ we can express $x_{t}$ as

$$
x_{t}=C \bar{Z}_{t-1}+D \bar{u}_{t}
$$

for some matrices $C$ and $D$. This can then be used to generate a historical time series for $x_{t}$. The stochastic process for the exogenous (structural) disturbances is then characterized by (10) - (11), together with a stochastic process for the VAR residuals $\bar{u}_{t}$ and an initial value for $\bar{Z} \cdot{ }^{51}$

\footnotetext{
${ }^{50}$ It is important that both vectors $\bar{Z}_{t}$ and $\tilde{Z}_{t}$ contain all relevant variables which are part of the information set at date $t$ (such as $\hat{Y}_{t+1}$ and $\pi_{t+1}$ ), for the previous equality to hold.

${ }^{51}$ Using (10) - (11) together with the structural equations of the model, the historical VAR residuals $\bar{u}_{t}$, and the appropriate initial value for $\bar{Z}$ reproduces exactly the historical time series of all variables.
} 
Table 4 contains the results of the counterfactual simulations for alternative policy rules and structural parameters and shock processes. It reports standard deviations of output, inflation, the interest rate, and the welfare-relevant output gap $E_{t-2}\left(\hat{Y}_{t}-\hat{Y}_{t}^{n}\right)$, where $\hat{Y}_{t}^{n}$ is the flexible-price level of output implied by the model. The upper part of the table reports counterfactual standard deviations for alternative combinations of the monetary policy parameters and the private sector parameters, using the shock processes for $g_{t}$ and $q_{t}$ estimated in Sample 1. The lower part of Table 4 reports the results of the same calculations, in the case that the shock processes are the ones estimated in Sample 2. The standard deviations reported refer asymptotic statistics so that they are not affected by the value of the initial vector $\bar{Z}$, but sample standard deviations yield similar qualitative results.

How important is the change of shock processes in explaining the "great moderation," i.e., the drop in observed output and inflation volatility in the post-80 period? Consistent with, e.g., Stock and Watson (2003), our experiments show that if the monetary policy of sample 2 had always been adopted, a change from shocks of period 1 to shocks of period 2 would have somewhat lowered the standard deviation of output and inflation (see rows 3-4 and 7-8 of Table 4). An entirely different picture emerges however if the monetary policy of sample 1 is maintained throughout. In fact, Table 4 suggests that the volatility of output and inflation increase substantially as we move to the shocks of sample 2 (see rows 1-2 and 5-6). This suggests that the "great moderation" cannot be explained solely, or even primarily with a change in exogenous shocks. In our setup, it is not only the size of shocks that has changed but also their mix. While the standard deviation of supply shocks falls from sample 1 to sample 2, the volatility of estimated real demand shocks increases.

Is the monetary policy then mainly responsible for the "great moderation"? If the shock processes of the pre- 80 sample had continued to prevail in the post- 80 period, then the shift from pre-80 $\left(\Delta_{1}^{M P}\right)$ to post-80 $\left(\Delta_{2}^{M P}\right)$ policy would not have affected the volatility of output much (see rows 1 and 3, or 2 and 4 of Table 4 ). With the shocks of sample 2, however, we 
see that this shift in policy can indeed explain a large drop in output volatility (see rows 6 and 8$) .52$

The story that emerges is thus not an all-shocks or an all-policy one, but a more subtle one. In order to explain the decline in inflation and output volatility, it is crucial for the policy rule to have changed the way it has, along with the shocks. To understand this, remember from the previous subsection that the post- 80 policy rule is particularly well suited to reduce output and inflation volatility in the face of demand shocks, but that it exacerbates output fluctuations due to supply shocks. Such a policy appears thus to have mitigated the effects of more important demand shocks in the post-80 sample. At the same time, output volatility has remained contained given relatively smaller supply shocks.

One may wonder next whether, for given shocks, the change in volatility is mostly due to the policy rule or to a change in structural parameters of the private sector. If the latter parameters had always been equal to those of the post-80 period $\left(\Delta_{2}^{P S}\right)$, a change in the monetary policy rule from $\Delta_{1}^{M P}$ to $\Delta_{2}^{M P}$ would have lowered the volatility of inflation, the output gap and the interest rate, regardless of the shock process. The post-80 policy rule increases slightly the volatility of output in the case of the shocks estimated for the sample 1, but lowers it importantly in the case of the shocks of estimated for the sample 2. Again this is due to the fact that supply shocks are relatively important in the first sample, while real demand shocks appear more important in the second sample.

Overall, these experiments suggest that the change in monetary policy has been instru-

\footnotetext{
${ }^{52}$ Stock and Watson (2003) perform a similar counterfactual experiment with several models, including the estimated model of Smets and Wouters (2004), which is related to the one considered here. By letting the monetary policy change from one that is supposed to characterize pre- 80 policy to the one estimated for the post- 80 period, they find that monetary policy does not account for much of the drop in output volatility. To reconcile their results with ours, it is important to note that the structural parameters and the shock processes that Stock and Watson use are based on the Smets and Wouters model estimated over the entire 1957-2002 sample. Consequently, they don't evaluate the importance of changes in the structural shock processes in the context of that model. Instead, our counterfactual experiments are done separately for both subsamples. Our results are consistent with those of Stock and Watson (2003) if we assume that the shock processes are those of the pre- 80 period, but not when they are those of the post- 80 period. Moreover, the pre- 80 policy rule that they consider is constrained to yield a determinate equilibrium, which might underestimate the role of the changes in monetary policy.
} 
mental in reducing the economy's variability in the post- 80 period. Note however that we are relatively conservative in terms of the importance that we attribute to the monetary policy rule. In fact, the estimation approach we adopted does not impose that the monetary policy shocks estimated by $(10)$ - (11) be orthogonal to the other shocks. One might argue that the monetary policy shocks $\varepsilon_{t}$ include systematic responses to other shocks. In the exercise above, we attribute all of these systematic responses to "shocks" and not to policy. By attributing instead these responses to policy, we find an even more important role for the policy rule in reducing the volatility of output and inflation. ${ }^{53}$ Once the residual monetary policy shocks are set equal to zero in the counterfactual experiments, the importance of the monetary policy rules in reducing volatility of output and inflation, becomes once again more important.

\section{Conclusion}

Empirical evidence from VAR analyses, including the one presented here, suggests that unexpected exogenous changes in the Fed funds rate have been followed by a smaller response of output and inflation since the beginning of the 1980's. In this paper, we have attempted to determine the causes of this phenomenon and the implications for the effectiveness of monetary policy. In addition, we have investigated to what extent the great reduction in output and inflation volatility can be explained by an alteration of shock processes, a change in the behavior the private sector, or a shift in monetary policy.

\footnotetext{
${ }^{53}$ Specifically, we regress the monetary policy shock $\varepsilon_{t}$ on the remaining shocks

$$
\varepsilon_{t}=\phi_{g} g_{t+1}+\phi_{q} E_{t} q_{t+1}+\nu_{t}
$$

to estimate a new monetary policy shock, $\nu_{t}$, that is by construction orthogonal to innovations in other real shocks. (Expanding this regression by including lags of $g_{t+1}$ and $E_{t} q_{t+1}$ does not change any of our results.) We then use the alternative vector of shocks $\hat{x}_{t}=\left[\nu_{t}, g_{t+1}, E_{t} q_{t+1}\right]^{\prime}$ and the appropriately modifed expression (11) to simulate our model. By combining the monetary policy rule (8) with (12), we effectively allow the interest rate to respond systematically to the real demand and supply shocks. Note that impulse responses to $\nu_{t}$ are the same as the impulse responses to $\varepsilon_{t}$ reported in Figures 1 and 2.
} 
We have focused on three dimensions of monetary policy effectiveness: 1) its success in eliminating non-fundamental sources of fluctuations; 2) its ability to stabilize the effects of shocks on the economy, and 3) the extent to which it manages to reduce the amount of randomness in the setting of its policy. Overall, we find that the dominant cause behind the alteration of the monetary transmission mechanism is a change in the conduct of monetary policy, characterized mainly by a stronger response to inflation expectations output since the early 1980's. The post-80 monetary policy rules prevents potential non-fundamental forces from affecting the economy. Moreover, our counterfactual experiments suggest that the policy response to monetary policy shocks and demand shocks has more effectively mitigated the effects on output and inflation since the early 1980's. In the face of supply shocks, though, we find that the post-80 policy reduces inflation fluctuations but exacerbates output fluctuations, so as to bring output closer to its natural rate. Changes in the variance of policy shocks have only played a negligible role. Taken together, we view these results as suggesting that monetary has become more effective at stabilizing the economy.

Counterfactual experiments reported here suggest that the change in monetary policy has also been instrumental in reducing observed output and inflation volatility in the post- 80 period. Consistent with other studies, the change in shocks has also played an important role. However while the size of the shocks has changed, their mix has also changed importantly. We find that a change in shocks only would not have reduced the volatility. Neither would a change in policy only have done it. The explanation found here is a more subtle one in which in order to explain the decline in inflation and output volatility, it is crucial for the policy rule to have changed the way it has, along with the shocks.

\section{References}

[1] Abel, Andrew B. (1990), "Asset Prices under Habit Formation and Catching Up with the Joneses," American Economic Review 80(2):38-42. 
[2] Ahmed, Shaghil, Andrew Levin, and Beth Anne Wilson (2004), "Recent U.S. Macroeconomic Stability: Good Policies, Good Practices, or Good Luck?" Review of Economics and Statistics 86(3): 824-832.

[3] Altig, David, Lawrence J. Christiano, Martin Eichenbaum, and Jesper Linde (2005), "Firm-Specific Capital, Nominal Rigidities and the Business Cycle," NBER working paper 11034 .

[4] Andrews, Donald W.K. (1993), "Tests of Parameter Instability and Structural Change with Unknown Change Point," Econometrica 61: 821-856.

[5] Amato, Jeffery D., and Thomas Laubach (2003), "Estimation and Control of an Optimization-Based Model with Sticky Prices and Wages," Journal of Economic Dynamics and Control 27(7): 1181-1215.

[6] —— , and —— (2004), "Implications of Habit Formation for Optimal Monetary Policy," Journal of Monetary Economics 51: 305-325.

[7] Bai, Jushan, Robin Lumsdaine and James Stock (1998), "Testing For and Dating Common Breaks in Multivariate Time Series," Review of Economic Studies 65: 395-432.

[8] Barth, Marvin J., and Valerie A. Ramey (2001), "The Cost Channel of Monetary Transmission," NBER Macroeconomics Annual 2001.

[9] Basu, Susanto, and Miles S. Kimball (2003), "Investment Planning Costs and the Effects of Fiscal and Monetary Policy," unpublished, University of Michigan.

[10] Bernanke, Ben S., and Alan S. Blinder (1992), "The Federal Funds Rate and the Transmission of Monetary Policy," American Economic Review, 82, 901-21.

[11] Bernanke, Ben, and Jean Boivin (2003), "Monetary Policy in a Data-Rich Environment," Journal of Monetary Economics 50(3): 525-546. 
[12] Bernanke, Ben, Jean Boivin and Piotr Eliasz (2005), "Measuring Monetary Policy: A Factor Augmented Vector Autoregressive (FAVAR) Approach," Quarterly Journal of Economics 120(1): 387-422.

[13] Bernanke, Ben S., Mark Gertler, and Mark W. Watson (1997), "Systematic Monetary Policy and the Effects of Oil Price Shocks," Brookings Papers on Economic Activity, $0(1), 91-142$.

[14] Bernanke, Ben S., and Ilian Mihov (1998), "Measuring Monetary Policy," Quarterly Journal of Economics, 113(3): 869-902.

[15] Blanchard, Olivier, and John Simon (2001), "The Long and Large Decline in U.S. Output Volatility," Brookings Papers on Economic Activity 1: 135-164.

[16] Blinder, Alan S. (1994), "On Sticky Prices: Academic Theories Meet the Real World," in N.G. Mankiw, ed., Monetary Policy, Chicago: University of Chicago Press.

[17] Boivin, Jean (1999), "Revisiting the Evidence on the Stability of Monetary VAR's", unpublished manuscript, Columbia University.

[18] — (2005), "Has U.S. Monetary Policy Changed? Evidence from Drifting Coefficients and Real-Time Data," NBER working paper 11314. (Forthcoming in Journal of Money, Credit and Banking).

[19] Boivin, Jean, and Marc P. Giannoni (2002), "Assessing Changes in the Monetary Transmission Mechanism: A VAR Approach," Federal Reserve Bank of New York, Economic Policy Review 8(1): 97-112.

[20] Boldrin, Michele, Lawrence J. Christiano, and Jonas D.M. Fisher (2001), "Habit Persistence, Asset Returns and the Business Cycle," American Economic Review 91(1): 149-166. 
[21] Calvo, Guillermo A. (1983), "Staggered Prices in a Utility-Maximizing Framework," Journal of Monetary Economics, 12(3), 383-98.

[22] Christiano, Lawrence J., Martin Eichenbaum, and Charles L. Evans (1999), "Monetary Policy Shocks: What Have we Learned and to What End?," in John B. Taylor and Michael Woodford (eds.), Handbook of Macroeconomics, Amsterdam: North-Holland, Volume 1A, Chapter 2.

[23] $\square,-\longrightarrow$, and $-\longrightarrow$ (2005), "Nominal Rigidities and the Dynamic Effect of a Shock to Monetary Policy," Journal of Political Economy 113(1): 1-45.

[24] Clarida, Richard, Jordi Galí, and Mark Gertler (2000), "Monetary Policy Rules and Macroeconomic Stability: Evidence and Some Theory," Quarterly Journal of Economics 115(1): $147-80$.

[25] Cogley, Timothy, and James M. Nason (1995), "Output Dynamics in Real-BusinessCycle Models," American Economic Review 85(3): 492-511.

[26] Cogley, Timothy, and Thomas J. Sargent (2001), "Evolving Post-World War II U.S. Inflation Dynamics," NBER Macreconomics Annual 16: 331-373.

[27] —— $\longrightarrow$, and $-\longrightarrow$ (2005), "Drifts and Volatilities: Monetary Policies and Outcomes in the Post WWII US," Review of Economic Dynamics 8: 262-302.

[28] Cook, Timothy (1989), "Determinants of the Federal-Funds Rate", FRB Richmond Economic Review 75(1): 3-19.

[29] Dixit, Avinash K., and Joseph E. Stiglitz (1977), "Monopolistic Competition and Optimum Product Diversity," American Economic Review 67: 297-308. 
[30] Dridi, Ramdan, Alain Guay, and Eric Renault (2005), "Indirect Inference and Calibration of Dynamic Stochastic General Equilibrium Models," Journal of Econometrics, forthcoming.

[31] Edge, Rochelle (2000), "Time-to-Build, Time-to-Plan, Habit Persistence and the Liquidity Effect," International Finance Discussion Paper no. 2000-673, Board of Governors of the Federal Reserve System.

[32] Federal Reserve Bank of New York (2002), "Financial Innovation and the Monetary Transmission," Economic Policy Review, 8(1).

[33] Forni, Mario, Marc Hallin, Marco Lippi, and Lucrezia Reichlin (2000), "The Generalized Dynamic Factor Model: Identification and Estimation," Review of Economics and Statistics 82:4, 540-554.

[34] Fuhrer, Jeffrey C. (2000), "Habit Formation in Consumption and Its Implications for Monetary-Policy Models," American Economic Review 90(3): 367-90.

[35] Fuhrer, Jeffrey C. and Geoffrey R. Moore (1995), "Inflation Persistence," The Quarterly Journal of Economics 110(1): 127-159.

[36] Galí, Jordi (1994), "Keeping Up with the Joneses: Consumption Externalities, Portfolio Choice, and Asset Prices," Journal of Money, Credit, and Banking 26(1): 1-8.

[37] Galí, Jordi, and Mark Gertler (1999), "Inflation Dynamics: A Structural Econometric Analysis," Journal of Monetary Economics 44(2): 195-222.

[38] Gertler, Mark, and Cara S. Lown (2000), "The Information in the High-Yield Bond Spread for the Business Cycle: Evidence and Some Implications," NBER working paper no. 7549 . 
[39] Giannoni, Marc. P. and Michael Woodford (2003), "How Forward-Looking is Optimal Monetary Policy?" Journal of Money, Credit, and Banking 35(6), Part 2: 1425-1469.

[40] —— and Michael Woodford (eds.), The Inflation-Targeting Debate, Chicago: University of Chicago Press, p. 93-162.

[41] Gilchrist, Simon, and John C. Williams (2000), "Putty-Clay and Investment: A Business Cycle Analysis," Journal of Political Economy 108(5): 928-60.

[42] Hall, Robert E. (2001), "Industry Dynamics with Adjustment Costs," unpublished, Hoover Institution and Stanford University, October.

[43] Hansen, Bruce E, (1997), "Appropriate Asymptotic $P$ Values for Structural-Change Tests," Journal of Business and Economic Statistics, 15(1): 60-67.

[44] Kahn, James, Margaret M. McConnell, and Gabriel Perez-Quiros (2002), "On the Causes of the Increased Stability of the U.S. Economy," Federal Reserve Bank of New York, Economic Policy Review 8(1): 183-202.

[45] Kilian, Lutz (1998), "Small-Sample Confidence Intervals for Impulse Response Functions," Review of Economics and Statistics 80(2): 218-230.

[46] King, Robert G., and Mark W. Watson (1998), "The Solution of Singular Linear Difference Systems under Rational Expectations," International Economic Review 39(4): $1015-26$.

[47] Kuttner Ken N., and Patricia C. Mosser (2002), "The Monetary Transmission Mechanism: Some Answers and Further Questions", Federal Reserve Bank of New York, Economic Policy Review 8(1): 15-26. 
[48] Kydland Finn E., and Edward C. Prescott (1982), "Time to Build and Aggregate Fluctuations," Econometrica 50(6): 1345-70.

[49] Lubik, Thomas A. and Frank Shorfheide (2004), "Testing for Indeterminacy: An Application to U.S. Monetary Policy," American Economic Review 94(1): 190-217.

[50] Lucas, Robert E., Jr. (1976), "Econometric Policy Evaluation: A Critique," CarnegieRochester Conference Series on Public Policy, 1: 19-46.

[51] McCallum, Bennett (1983), "On Non-Uniqueness in Rational Expectations Models: An Attempt at Perspective," Journal of Monetary Economics 11: 139-168.

[52] —— (1998), "Solutions to linear rational expectations models: a compact exposition," Economic Letters, 61, 143-147.

[53] —— , and Edward Nelson (1999), "Performance of Operational Policy Rules in an Estimated Semi-Classical Structural Model," in J. B. Taylor, ed., Monetary Policy Rules, Chicago: University of Chicago Press.

[54] McConnell, Margaret M., and Gabriel Perez-Quiros (2000), "Output Fluctuations in the United States: What Has Changed Since the Early 1980's?," American Economic Review 90(5): 1464-76.

[55] Ramey, Valerie A., and Daniel J. Vine (2003), "Tracking the Source of the Decline in GDP Volatility: An Analysis of the Automobile Industry," manuscript, UCSD.

[56] Rotemberg, Julio J., and Michael Woodford (1997), "An Optimization-Based Econometric Framework for the Evaluation of Monetary Policy," NBER Macroeconomics Annual 1997: 297-346.

[57] Sims, Christopher A. (1992), "Interpreting the Macroeconomic Time Series Facts: The Effects of Monetary Policy," European Economic Review, 36(5), 975-1000. 
[58] Sims, Christopher A., and Tao Zha (2005), "Were there Regime Switches in US Monetary Policy?" manuscript, Princeton University (available at www.princeton.edu/ $\sim \operatorname{sims})$.

[59] Smets, Frank, and Raf Wouters (2003), "An Estimated Stochastic Dynamic General Equilibrium Model for the Euro Area," Journal of the European Economic Association 1(5): 1123-1175.

[60] Smets, Frank, and Raf Wouters (2004), "Shocks and Frictions in US Business Cycles: A Bayesian DSGE Approach," manuscript, April.

[61] Stock, James H. and Mark W. Watson (1996), "Evidence on Structural Instability in Macroeconomic Time Series Relations," Journal of Business and Economic Statistics 14: $11-30$.

[62] —— , and —— (1998), "Median Unbiased Estimation of Coefficient Variance in a Time-Varying Parameter Model," Journal of the American Statistical Association 93: $349-358$.

[63] —— and —— (2002), "Has the Business Cycle Changed and Why?" NBER Macroeconomics Annual 2002: 159-218.

[64] —— and —— (2003), "Has the Business Cycle Changed? Evidence and Explanations," in Monetary Policy and Uncertainty, Federal Reserve Bank of Kansas City: 9-56.

[65] Taylor, John B. (1993), "Discretion versus Policy Rules in Practice," Carnegie-Rochester Conference Series on Public Policy 39: 195-214.

[66] Woodford, Michael (1999), "Optimal Monetary Policy Inertia," NBER working paper no. 7261 . 
[67] —— (2001), "The Taylor Rule and Optimal Monetary Policy," American Economic Review 91(2): 232-237.

[68] — (2003), Interest and Prices: Foundations of a Theory of Monetary Policy, Princeton: Princeton University Press.

[69] — (2005), "Firm-Specific Capital and the New Keynesian Phillips Curve," International Journal of Central Banking 1(2): 1-46. 


\section{A Robustness analysis of VAR results}

In this Appendix we investigate the robustness of the VAR findings reported in Section 2, to the inclusion of more information in the VAR and to the choice of an alternative starting date for the second sample, namely 1984:1.

The specification used in this paper was favored on the ground that it contained the minimum set of variables necessary for our investigation, while delivering sensible responses of the economy consistent with existing results. As is commonly done in this literature, the commodity price index was included to alleviate the so-called price puzzle. Yet, our VAR does contain a limited amount information and this potential misspecification could contaminate our empirical results. Bernanke and Boivin (2003) and Bernanke, Boivin and Eliasz (2005) propose a way of incorporating more information in low dimensional VARs. More specifically, building on recent development on the estimation dynamic factor models with large panels, ${ }^{54}$ their strategy is to expand VAR systems with a few factors estimated from a large panel of macroeconomic series. We follow the exact same factor-augmented VAR (FAVAR) strategy here, expanding a VAR in $\left\{\hat{Y}_{t}, \pi_{t}, R_{t}\right\}$ with the first factor estimated from the panel of macroeconomic series used in Bernanke, Boivin and Eliasz (2005). ${ }^{55}$ Note that if this factor properly accounts for the existing information, there is no justification to have the commodity price index in the VAR, which we thus exclude. ${ }^{56}$ It is important to note that if the baseline VAR is properly specified, the inclusion of additional information should not affect the results.

We estimate the impulse response functions for the FAVAR model for the two samples considered in the text, as well as a third one corresponding to the alternative break date, that is the post-84:1 period. The results are reported in Figure 3 together with those obtained

\footnotetext{
${ }^{54}$ See Stock and Watson (2002), Forni, Lippi and Reichlin (2000) among others.

${ }^{55}$ See Bernanke, Boivin and Eliasz (2005) for details on the implementation, the data set and the identification strategy - consistent with our VAR - in this framework.

${ }^{56}$ In fact, adding the commodity price index on top of the factor does not affect the result. These results are not reported.
} 
from the VAR specification used in the paper. The confidence intervals displayed are those obtained from the baseline VAR.

Looking first at the results for the baseline VAR model - the -+- line in the figure we observe that the reduced effect of a monetary policy shock in the post- 80 period is robust to the alternative break date considered. But, there are still notable differences between the post- 80 and post- 84 samples. In particular, the response of inflation appears somewhat stronger when the VAR is estimated on the latter, and the response of output is positive for most of the periods in the first two years following a positive innovation to the Fed funds rate. We feel that this latter feature of the post-84 impulse response functions is problematic. In fact, it implies that over the first two years, a tightening of monetary policy results mainly in an expansionary effect on the economy, which is inconsistent with the implications of any standard macroeconomic model. This might suggest misspecification of our baseline VAR for the post-84, but given the much larger confidence interval, this could also be due to the imprecision of the estimation on this shorter sample.

Turning now to the results obtained from the FAVAR model, two key conclusions emerge. First, for the pre- and post- 80 periods - the first two columns in the figure - the results are essentially the same as those obtained with the baseline specification. There is a somewhat stronger response of output in the pre- 80 period that goes outside the confidence intervals of the baseline VAR; but this would reinforce our finding that there has been an important reduction in the effect of monetary policy shocks on output. The second conclusion is that the results of the baseline VAR for the post-84 period are not robust to the inclusion of the additional information. More strikingly, the inclusion of the factor has the effect of reversing the sign of the response of output, thus becoming consistent with conventional wisdom and with the results from the other samples. This suggests that more information was used in the conduct of monetary policy in the post- 84 period, which needs to be accounted for in order to properly identify the impulse response functions. 
Overall, this robustness analysis suggests that the pre- and post-80 comparison undertaken in the paper is justified, as the inclusion of more information does not affect the VAR conclusions for these two samples and makes the conclusions obtained from the post-84 period broadly consistent with those of the post-80 period.

\section{B Details on the structural model}

As indicated in section 3.1, each household seeks to maximizes its utility (3). Following Dixit and Stiglitz (1977), we assume that each household's aggregate consumption index is of the form

$$
C_{t}^{j}=\left(\int_{0}^{1} c_{t}^{j}(z)^{\frac{\theta-1}{\theta}}\right)^{\frac{\theta}{\theta-1}}
$$

with a constant elasticity of substitution between goods, $\theta>1$. It follows that optimal consumption of the good $z$ is given by the usual expression $c_{t}^{j}(z)=C_{t}^{j}\left(p_{t}(z) / P_{t}\right)^{-\theta}$, where $p_{t}(z)$ is the price of good $z$ at date $t$, and $P_{t}$ is the corresponding Dixit-Stiglitz price index. Since financial markets are assumed to be complete, all households face an identical intertemporal budget constraint, and choose to consume the same amount at any date. We may therefore drop the superscript $j$ in $C_{t}^{j}$. Furthermore, we assume as in Rotemberg and Woodford (1997) that households must choose the index $C_{t}$ at date $t-2$. The household's optimal choice of expenditure satisfies

$$
E_{t-2}\left\{\Lambda_{t} P_{t}\right\}=E_{t-2}\left\{u_{c}\left(C_{t}-\tilde{\eta} C_{t-1} ; \xi_{t}\right)-\beta \tilde{\eta} u_{c}\left(C_{t+1}-\tilde{\eta} C_{t} ; \xi_{t+1}\right)\right\}
$$

where $\Lambda_{t}$ represents the household's marginal utility of additional nominal income at date $t$. This equation indicates that at date $t-2$, the household chooses a level of expenditure $C_{t}$ for period $t$ that equates the expected utility of additional expenditure with the expected marginal utility of additional nominal income. While the first term on the right-hand side of (14) represents the expected effect of a change in expenditure at date $t$ on instantaneous 
utility at that date, the second term represents the effect of a change in $C_{t}$ on instantaneous utility in the following period, through its effect on the stock of habit. The marginal utilities of income furthermore satisfy

$$
\Lambda_{t}=\beta\left(1+R_{t}\right) E_{t} \Lambda_{t+1}
$$

where $R_{t}$ is the rate of return on a riskless nominal one-period asset. In addition, we assume that the government purchases an aggregate $G_{t}$ of all goods in the economy of the form (13). This implies that the demand for good $z$ is given by

$$
y_{t}(z)=Y_{t}\left(\frac{p_{t}(z)}{P_{t}}\right)^{-\theta}
$$

where the aggregate demand for the composite good, $Y_{t}$, satisfies $Y_{t}=C_{t}+G_{t}$.

We consider first-order approximations of (14), (15) and the goods market equilibrium condition around a steady state in which there are no exogenous disturbances and prices are stable. This yields

$$
\begin{aligned}
E_{t-2}\left\{\hat{\lambda}_{t}\right\} & =-\sigma_{c}^{-1}(1-\beta \tilde{\eta})^{-1} E_{t-2}\left[\left(1+\beta \tilde{\eta}^{2}\right) \hat{C}_{t}-\tilde{\eta} \hat{C}_{t-1}-\beta \tilde{\eta} \hat{C}_{t+1}-\bar{C}_{t}+\beta \tilde{\eta} \bar{C}_{t+1}\right](17) \\
\hat{\lambda}_{t} & =E_{t}\left(\hat{\lambda}_{t+1}+\hat{R}_{t}-\pi_{t+1}\right) \\
\hat{Y}_{t} & =(\bar{C} / \bar{Y}) \hat{C}_{t}+\hat{G}_{t}
\end{aligned}
$$

where $\hat{\lambda}_{t}, \hat{C}_{t}, \hat{Y}_{t}$, and $\hat{R}_{t}$ represent respectively percent deviations of $\left(\Lambda_{t} P_{t}\right), C_{t}, Y_{t}$, and $1+R_{t}$ from their steady-state level, $\hat{G}_{t} \equiv\left(G_{t}-\bar{G}\right) / \bar{Y}, \pi_{t} \equiv \log \left(P_{t} / P_{t-1}\right)$, and $\bar{C}_{t} \equiv \sigma_{c} \frac{u_{c \xi}}{u_{c}} \xi_{t}$ represents exogenous shifts in marginal utility of consumption, and $\sigma_{c} \equiv-u_{c} /\left(u_{c c} \bar{C}\right)>0$. Interating (18) forward, we obtain $\hat{\lambda}_{t}=\hat{r}_{t}^{L}$ where $\hat{r}_{t}^{L}$ is defined in (5) in the text. Combining this with (17) and (19) to eliminate $\hat{C}_{t}$, and recalling that $E_{t-2} \hat{C}_{t}=\hat{C}_{t}$, we get (4).

To obtain the aggregate supply equation (6), we note that since every supplier faces the same demand function given by (16), all suppliers allowed to change their price in period $t$ 
choose the same price $p_{t}^{*}$ that maximizes

$$
E_{t-1} \sum_{T=t}^{\infty}(\alpha \beta)^{T-t}\left[\Lambda_{T} p_{t}^{*}\left(\frac{P_{T-1}}{P_{t-1}}\right)^{\gamma} Y_{T}\left(\frac{p_{t}^{*}\left(\frac{P_{T-1}}{P_{t-1}}\right)^{\gamma}}{P_{T}}\right)^{-\theta}-v\left(Y_{T}\left(\frac{p_{t}^{*}\left(\frac{P_{T-1}}{P_{t-1}}\right)^{\gamma}}{P_{T}}\right)^{-\theta} ; \xi_{T}\right)\right] .
$$

While the first term inside the brackets represents the contribution to expected utility from sales revenues at date $T$, given that the seller chooses a price $p_{t}^{*}$, the second term represents disutility resulting from the supply of goods demanded at date $T$. The household discounts the stream of utilities by a factor $\alpha \beta$ to account for the fact that the price chosen at date $t$ will apply in period $T$ with probability $\alpha^{T-t}$. Log-linearizing the first-order condition to this problem and solving for $\hat{p}_{t}^{*} \equiv \log \left(p_{t}^{*} / P_{t}\right)$ yields

$$
\hat{p}_{t}^{*}=E_{t-1}\left\{\sum_{T=t}^{\infty}(\alpha \beta)^{T-t}\left[\left(\pi_{T}-\gamma \pi_{T-1}\right)+\frac{1-\alpha \beta}{1+\omega \theta} \hat{s}_{T}\right]-\left(\pi_{t}-\gamma \pi_{t-1}\right)\right\}
$$

where $\omega \equiv v_{y y} \bar{Y} / v_{y}>0, \hat{s}_{t} \equiv \omega \hat{Y}_{t}-\hat{\lambda}_{t}-q_{t}$ represents percent deviations from steady-state of the average (across firms) real marginal cost, and $q_{t} \equiv-\frac{v_{y \xi}}{v_{y}} \xi_{t}$. It can be shown that $\hat{s}_{t}$ relates to a measure of the output gap defined as the percent deviation of output from its natural rate whereby the natural rate we mean the equilibrium output that would obtain in the absence of price rigidities. ${ }^{57}$ Quasi-differentiating (20) yields the optimal pricing decision

$$
\hat{p}_{t}^{*}=\alpha \beta E_{t-1} \hat{p}_{t+1}^{*}+\frac{1-\alpha \beta}{1+\omega \theta} E_{t-1} \hat{s}_{t}+\alpha \beta E_{t-1}\left(\pi_{t+1}-\gamma \pi_{t}\right)
$$

Assuming furthermore that the price-setters who are allowed to change their price are chosen

\footnotetext{
${ }^{57}$ This is most easily seen in the absence of habit persistence, $\eta=0$. Using (17) and (19) in this case to substitute for $\hat{\lambda}_{t}$, we can write

$$
E_{t-2} \hat{s}_{t}=\left(\omega+\sigma^{-1}\right) E_{t-2}\left(\hat{Y}_{t}-\hat{Y}_{t}^{n}\right)
$$

where $\sigma=\sigma_{c}(\bar{C} / \bar{Y})$, and $\hat{Y}_{t}^{n}=\left(\omega+\sigma^{-1}\right)^{-1}\left[\sigma^{-1}\left(\hat{G}_{t}+(\bar{C} / \bar{Y}) \bar{C}_{t}\right)+q_{t}\right]$ indicates percent deviations from steady state of the natural rate of output. In the presence of habit formation, however, the real marginal cost relates to expected output gaps at current, future and past periods (see Giannoni and Woodford, 2004).
} 
independently of their history of price changes implies that the price index satisfies

$$
P_{t}=\left\{(1-\alpha) p_{t}^{* 1-\theta}+\alpha\left[P_{t-1}\left(P_{t-1} / P_{t-2}\right)^{\gamma}\right]^{1-\theta}\right\}^{1 /(1-\theta)}
$$

Log-linearizing this law of motion for $P_{t}$, and combining the resulting expression with (21) yields (6). 
Table 1: Hansen $J$-test for the different horizons

\begin{tabular}{cccccc}
\hline \hline & \multicolumn{5}{c}{$h_{y}$} \\
\cline { 2 - 6 }$h_{\pi}$ & 0 & 1 & 2 & 3 & 4 \\
\hline \multicolumn{6}{c}{$1959: 1-1979: 2$} \\
0 & 0.001 & 0.007 & 0.013 & 0.009 & 0.003 \\
1 & 0.000 & 0.000 & 0.000 & 0.000 & 0.000 \\
2 & 0.012 & 0.029 & 0.021 & 0.023 & 0.027 \\
3 & 0.053 & 0.015 & 0.003 & 0.005 & 0.003 \\
4 & 0.011 & 0.007 & 0.001 & 0.001 & 0.000 \\
\hline \multicolumn{6}{c}{$1979: 3-2002: 2$} \\
& \multicolumn{7}{c}{} \\
0 & 0.009 & 0.017 & 0.022 & 0.024 & 0.030 \\
1 & 0.013 & 0.003 & 0.003 & 0.002 & 0.005 \\
2 & 0.307 & 0.278 & 0.250 & 0.307 & 0.258 \\
3 & 0.005 & 0.002 & 0.003 & 0.009 & 0.009 \\
4 & 0.000 & 0.000 & 0.000 & 0.000 & 0.000 \\
\hline
\end{tabular}

Note: The table reports for each forecasting horizon combination $\left(h_{\pi}, h_{y}\right)$, the $p$-value of the Hansen $J$-test. A $p$-value smaller than 0.05 signifies that the model specification is rejected at the 5 percent level. See text for details. 


\section{Table 2: Estimates of structural parameters}

\begin{tabular}{cc|c}
\hline \hline Parameters & Sample 1 & Sample 2 \\
\hline Calibrated & & \\
$\beta$ & 0.99 & 0.99 \\
$\omega$ & 0.47 & 0.47 \\
\hline Estimated & & \\
$\psi$ & 0.495 & 0.662 \\
$\eta$ & $(0.048)$ & $(0.115)$ \\
& 0.502 & 0.500 \\
$\xi$ & $(-)$ & $(0.035)$ \\
& 0.011 & 0.008 \\
$\gamma$ & $(0.001)$ & $(0.002)$ \\
& 1 & 1 \\
$\phi_{\pi}$ & $(-)$ & $(-)$ \\
& 0.276 & 0.508 \\
$\phi_{y}$ & $(0.007)$ & $(0.050)$ \\
& 0.000 & 0.000 \\
$\rho_{1}$ & $(0.004)$ & $(0.038)$ \\
& 1.011 & 0.602 \\
$\rho_{2}$ & $(0.017)$ & $(0.015)$ \\
& -0.274 & -0.055 \\
& $(0.015)$ & $(0.016)$ \\
\hline & &
\end{tabular}

Note: Results based on the minimum distance estimation described in the text. Standard errors are in parentheses. (-) denotes that the standard error is not available because the parameter is hitting the boundary of the parameter space.

\section{Table 3: Indeterminacy in counterfactual experiments}

\begin{tabular}{cc|c}
\hline \hline & $\Delta_{1}^{P S}$ & $\Delta_{2}^{P S}$ \\
\hline$\Delta_{1}^{M P}$ & $\mathrm{I}$ & $\mathrm{I}$ \\
$\Delta_{2}^{M P}$ & $\mathrm{D}$ & $\mathrm{D}$ \\
\hline
\end{tabular}

Note: This table reports whether the structural model results in a determinate (D) equilibrium or an indeterminate (I) equilibrium for various combinations of policy rule coefficients $\left(\Delta_{s}^{M P}\right)$ and parameters of the private sector $\left(\Delta_{s}^{P S}\right)$, in samples $s=1,2$. 
Table 4: Standard deviations of output, inflation, interest rate and the output gap in counterfactual experiments

\begin{tabular}{ccc|c|c|c}
\hline \hline & \multicolumn{5}{c}{ Sample 1 shock process (pre-1980) } \\
Row \# & Parameter combination & $\operatorname{Sd}(\hat{Y})$ & $\operatorname{Sd}(\pi)$ & $\operatorname{Sd}(\hat{R})$ & $\operatorname{Sd}\left\{E\left(\hat{Y}-\hat{Y}^{n}\right)\right\}$ \\
\hline 1 & $\left(\Delta_{1}^{M P}, \Delta_{1}^{P S}\right)$ & 3.64 & 2.46 & 2.21 & 9.40 \\
2 & $\left(\Delta_{1}^{M P}, \Delta_{2}^{P S}\right)$ & 2.84 & 5.13 & 4.69 & 11.65 \\
3 & $\left(\Delta_{2}^{M P}, \Delta_{1}^{P S}\right)$ & 4.92 & 2.52 & 3.13 & 9.22 \\
4 & $\left(\Delta_{2}^{M P}, \Delta_{2}^{P S}\right)$ & 2.90 & 1.32 & 1.82 & 11.30 \\
\hline
\end{tabular}

Sample 2 shock process (post-1980)

\begin{tabular}{ccc|c|c|c} 
& & $\operatorname{Sd}(\hat{Y})$ & $\operatorname{Sd}(\pi)$ & $\operatorname{Sd}(\hat{R})$ & $\operatorname{Sd}\left\{E\left(\hat{Y}-\hat{Y}^{n}\right)\right\}$ \\
\hline 5 & $\left(\Delta_{1}^{M P}, \Delta_{1}^{P S}\right)$ & 4.15 & 7.70 & 6.36 & 8.32 \\
6 & $\left.\Delta_{1}^{M P}, \Delta_{2}^{P S}\right)$ & 10.46 & 12.61 & 11.45 & 13.29 \\
7 & $\left(\Delta_{2}^{M P}, \Delta_{1}^{P S}\right.$ & 4.73 & 2.51 & 3.66 & 6.69 \\
8 & $\left(\Delta_{2}^{M P}, \Delta_{2}^{P S}\right)$ & 1.71 & 0.93 & 1.78 & 8.02 \\
\hline
\end{tabular}

Note: The table reports counterfactual asymptotic standard deviations for alternative combinations of the shock processes, monetary policy coefficients and the private sector parameters. All numbers are expressed in percent. Standard deviations for inflation and the interest rate are annualized. 
Figure 1. VAR and Model-Based Impulse Responses to a Same-Size Monetary Shock
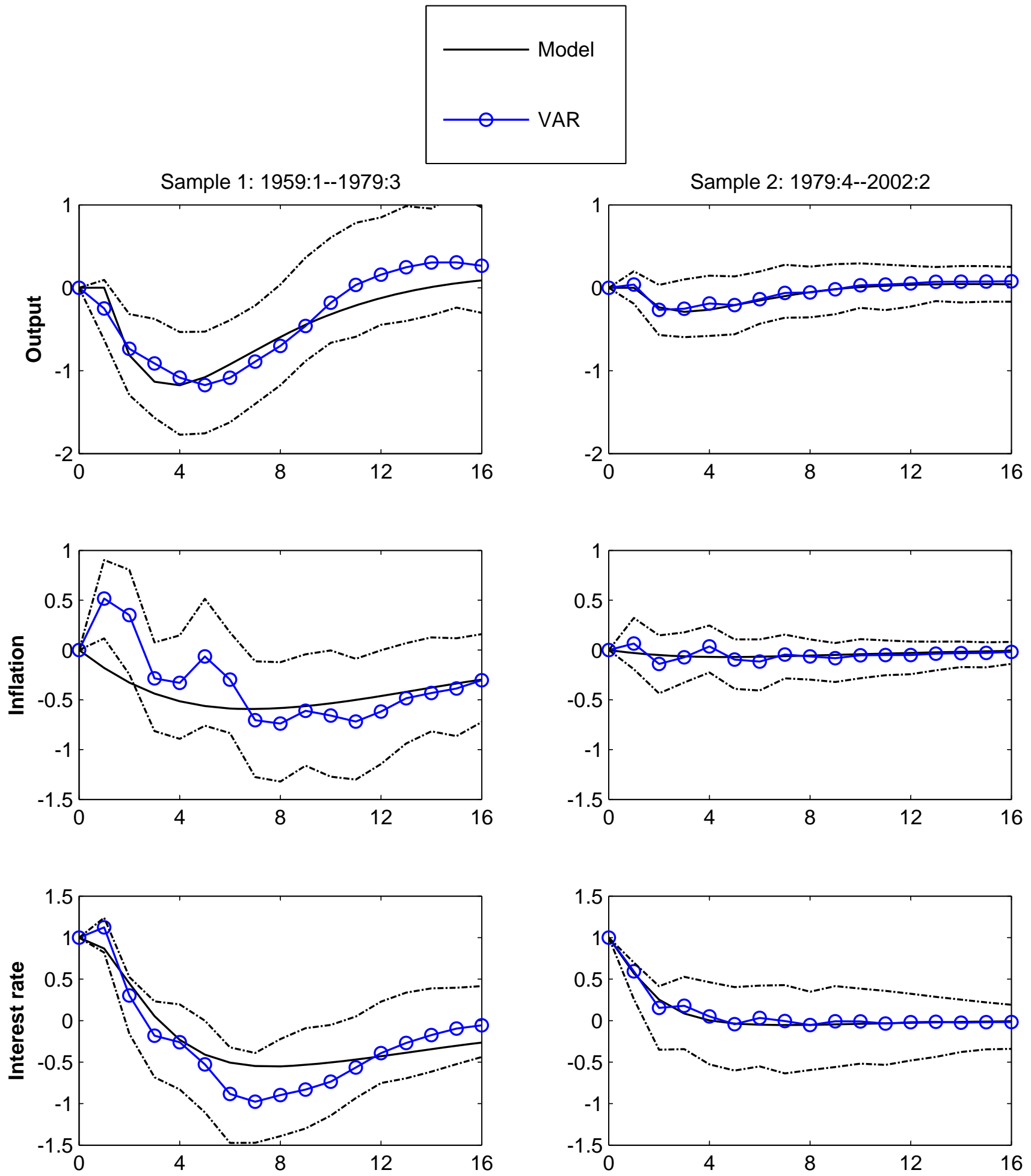


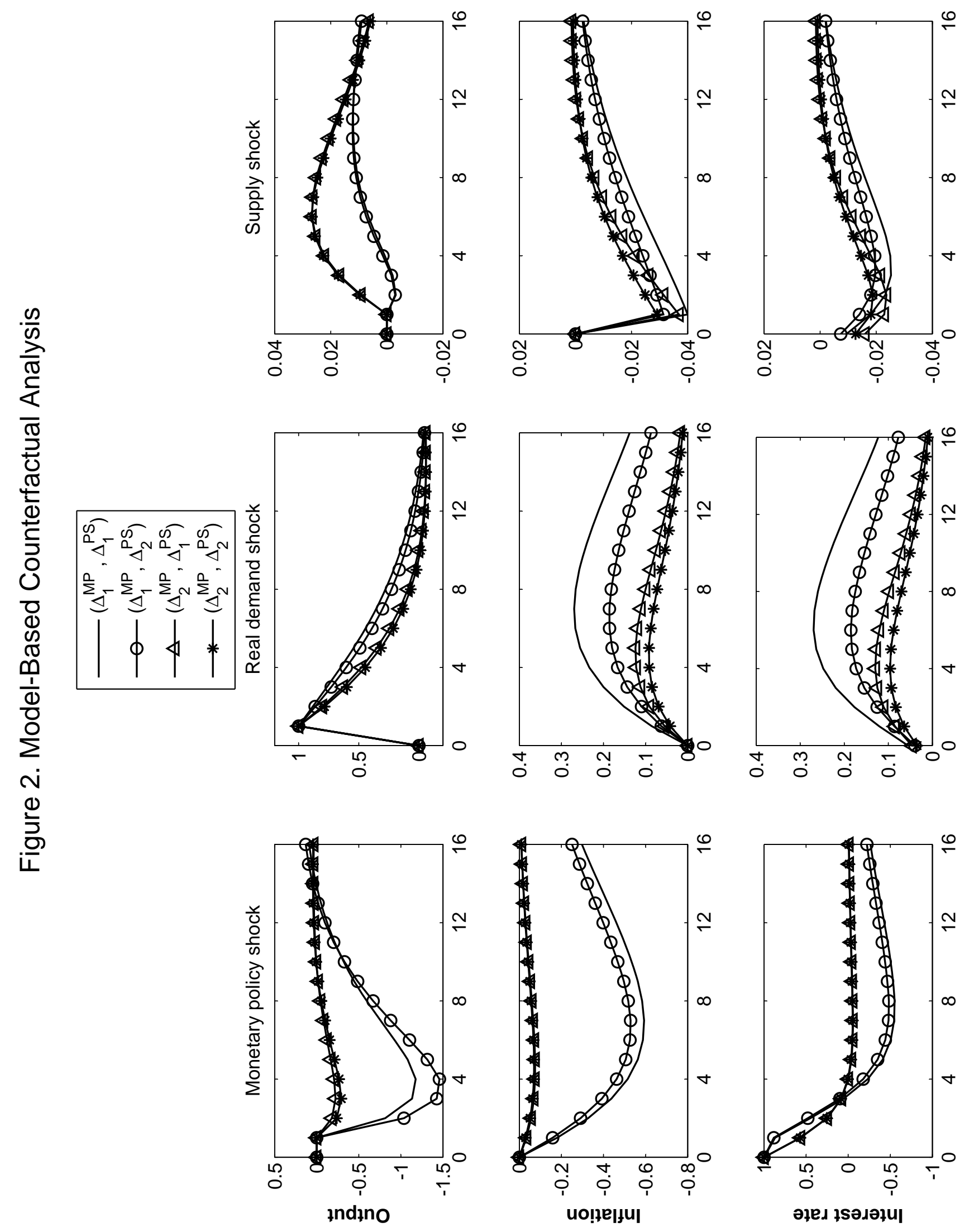



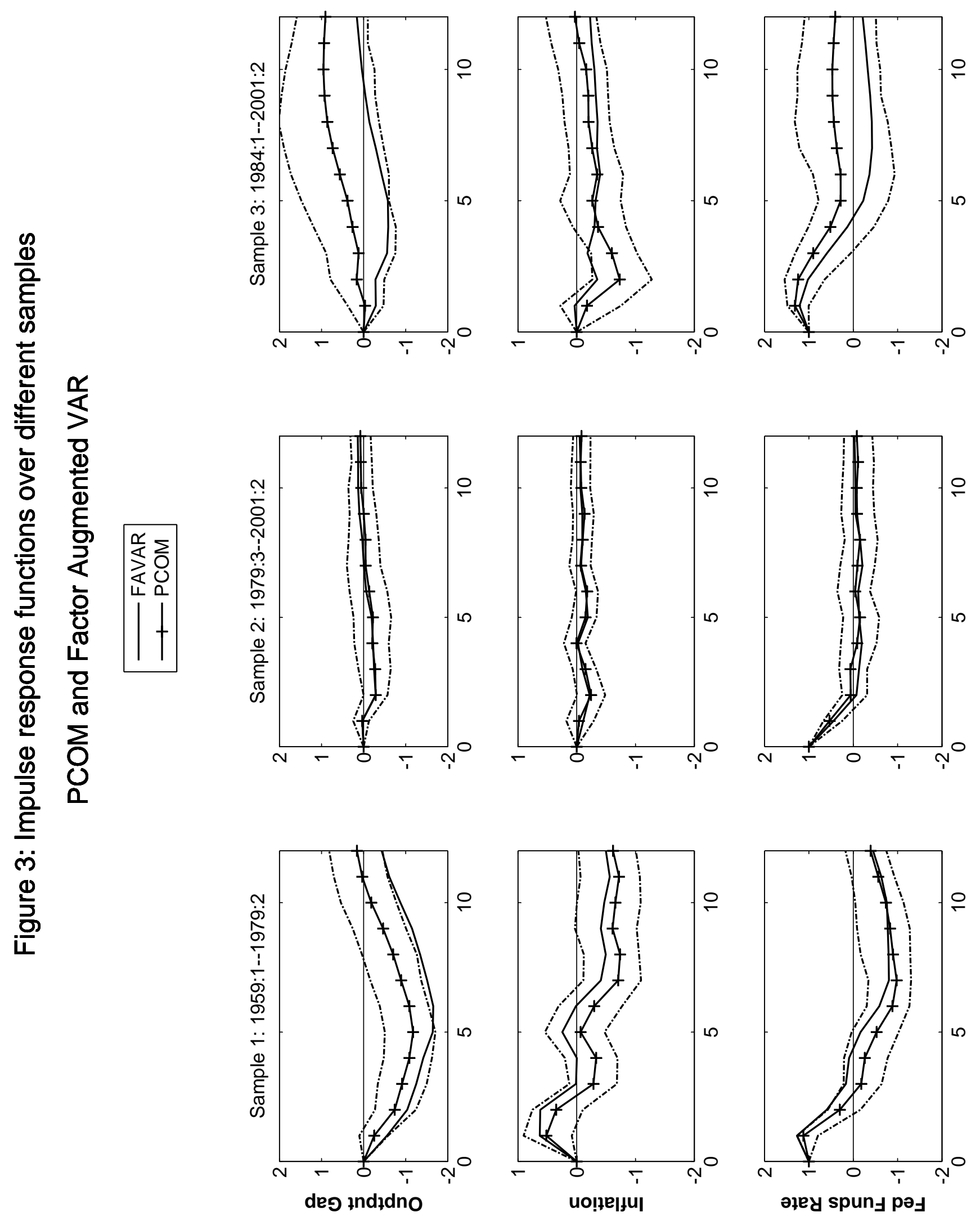